\title{
DNA methylation atlas and machinery in the developing and regenerating annelid Platynereis dumerilii
}

\author{
Anabelle Planques ${ }^{1}$, Pierre Kerner ${ }^{1}$, Laure Ferry $^{2}$, Christoph Grunau $^{3}$, Eve Gazave $^{1 *}$ and Michel Vervoort ${ }^{1^{*}}$ (D)
}

\begin{abstract}
Background: Methylation of cytosines in DNA ( $5 \mathrm{mC}$ methylation) is a major epigenetic modification that modulates gene expression and constitutes the basis for mechanisms regulating multiple aspects of embryonic development and cell reprogramming in vertebrates. In mammals, $5 \mathrm{mC}$ methylation of promoter regions is linked to transcriptional repression. Transcription regulation by $5 \mathrm{mC}$ methylation notably involves the nucleosome remodeling and deacetylase complex (NuRD complex) which bridges DNA methylation and histone modifications. However, less is known about regulatory mechanisms involving $5 \mathrm{mC}$ methylation and their function in nonvertebrate animals. In this paper, we study $5 \mathrm{mC}$ methylation in the marine annelid worm Platynereis dumerilii, an emerging evolutionary and developmental biology model capable of regenerating the posterior part of its body post-amputation.
\end{abstract}

Results: Using in silico and experimental approaches, we show that $P$. dumerilii displays a high level of DNA methylation comparable to that of mammalian somatic cells. $5 \mathrm{mC}$ methylation in P. dumerilii is dynamic along the life cycle of the animal and markedly decreases at the transition between larval to post-larval stages. We identify a full repertoire of mainly single-copy genes encoding the machinery associated with $5 \mathrm{mC}$ methylation or members of the NuRD complex in P. dumerilii and show that this repertoire is close to the one inferred for the last common ancestor of bilaterians. These genes are dynamically expressed during P. dumerilii development and regeneration. Treatment with the DNA hypomethylating agent Decitabine impairs $P$. dumerilii larval development and regeneration and has long-term effects on post-regenerative growth.

Conclusions: Our data reveal high levels of $5 \mathrm{mC}$ methylation in the annelid P. dumerilii, highlighting that this feature is not specific to vertebrates in the bilaterian clade. Analysis of DNA methylation levels and machinery gene expression during development and regeneration, as well as the use of a chemical inhibitor of DNA methylation, suggest an involvement of $5 \mathrm{mC}$ methylation in P. dumerilii development and regeneration. We also present data indicating that $P$. dumerilii constitutes a promising model to study biological roles and mechanisms of DNA methylation in non-vertebrate bilaterians and to provide new knowledge about evolution of the functions of this key epigenetic modification in bilaterian animals.

Keywords: Epigenetics, DNA methylation, 5mC, Regeneration, Development, Annelids, Evolution

\footnotetext{
* Correspondence: eve.gazave@ijm.fr; michel.vervoort@ijm.fr

Eve Gazave and Michel Vervoort are co-senior authors.

${ }^{1}$ Université de Paris, CNRS, Institut Jacques Monod, F-75006 Paris, France

Full list of author information is available at the end of the article
}

\section{$\triangle B M C$}

(c) The Author(s). 2021 Open Access This article is licensed under a Creative Commons Attribution 4.0 International License, which permits use, sharing, adaptation, distribution and reproduction in any medium or format, as long as you give appropriate credit to the original author(s) and the source, provide a link to the Creative Commons licence, and indicate if changes were made. The images or other third party material in this article are included in the article's Creative Commons licence, unless indicated otherwise in a credit line to the material. If material is not included in the article's Creative Commons licence and your intended use is not permitted by statutory regulation or exceeds the permitted use, you will need to obtain permission directly from the copyright holder. To view a copy of this licence, visit http://creativecommons.org/licenses/by/4.0/ The Creative Commons Public Domain Dedication waiver (http://creativecommons.org/publicdomain/zero/1.0/) applies to the data made available in this article, unless otherwise stated in a credit line to the data. 


\section{Background}

Epigenetic modifications or marks refer to any transient chemical alterations of nucleic acids or histones, which do not modify the primary nucleic acid sequence and which can be transmitted from one generation of cells (and in some cases of organisms) to the next [1,2]. Epigenetic marks regulate gene expression and therefore are of paramount importance to most aspects of the biology of living organisms, including during development, regeneration, and stem cell maintenance in animals [3, 4].

DNA methylation is an important epigenetic modification, found in the three domains of life, and has been the subject of intense study for many years [5-9]. In animals, DNA methylation mainly occurs through the covalent addition of a methyl group on position 5 of a cytosine to form 5-methyl-cytosine $(5 \mathrm{mC}) .5 \mathrm{mC}$ are mostly (or even exclusively in some species) found in cytosine-guanine dinucleotides, known as CpG sequences [10]. Abundance and distribution of $5 \mathrm{mC}$ strongly vary in different animal lineages. For example, in mammals, about $70-80 \%$ of CpGs throughout the genome are methylated in somatic tissue types. Unmethylated regions are largely restricted to dense clusters of CpGs, known as CpG islands (CGIs), which account for roughly two-thirds of mammalian gene promoters. In the rare cases where CGI promoters are highly methylated, genes are stably transcriptionally repressed. In many non-vertebrates, methylated CpGs are mostly found within gene bodies (transcribed regions) $[11,12]$. The function(s) of this form of DNA methylation, which is referred to as "gene body methylation" (and which is also found in vertebrates), is still largely unknown, but it has been hypothesized that it could be involved in homeostatic regulation of gene transcription [13]. $5 \mathrm{mC}$ are also often found in repetitive sequences and have been shown to be important for repressing the activity of transposable elements [7, 9].

DNA $5 \mathrm{mC}$ presence and roles rely on the activity of several classes of proteins that can be functionally classified according to their role: methylases that promote addition of methyl groups ("Writers"); proteins that oxidize $5 \mathrm{mC}$ and stimulate demethylation ("Modifiers"); and proteins that bind to methylated nucleotides, allowing interpretation of the encoded information, for example in terms of gene expression ("Readers") $[5,14]$ (Additional file 1: Fig. S1). Deposition of $5 \mathrm{mC}$ marks on DNA requires the action of evolutionarily conserved DNA methyltransferases (Dnmts) [15]. In mammals, three families of Dnmts are found (Dnmt1, 2, and 3), each of which play specific roles $[5,7]$. Dnmt3 proteins are involved in the de novo addition of $5 \mathrm{mC}$, while another member of the family, Dnmt1, maintains the methylation pattern during replication. Dnmt1 function involves Uhrf1 (Ubiquitin Like with PHD And Ring
Finger Domains 1 protein) which binds to both hemimethylated DNA and Dnmt1, thereby recruiting Dnmt1 to methylated DNA sites [16]. Dnmt2 (also referred to as tRNA aspartic acid methyltransferase 1) is a tRNAmethylating enzyme seemingly not involved in DNA methylation, at least in mammals [17]. DNA demethylation, which results in the recovery of non-methylated cytosines, occurs either passively during cell division and DNA replication (in the absence of Dnmt1 function) or actively thanks to the Ten-Eleven Translocation (Tet) family enzymes and G/T Mismatch-Specific Thymine DNA Glycosylase (Tdg) proteins [18, 19].

A series of proteins, known as methyl-CpG binding proteins (Mbp), recognize and bind methylated CpGs, acting as readout of DNA methylation by recruiting chromatin remodelers $[20,21]$. One key family of Mbp are methyl-CpG-binding domain (Mbd) proteins, which are found in many animals [22]. In mammals, seven members of this family are found, and they mostly promote transcriptional silencing by interacting with a wide array of histone methylases and deacetylases [20, 21]. $\mathrm{Mbd} 2$ and Mbd3 are part of the nucleosome remodeling and deacetylase complex (NuRD complex), which bridges DNA methylation and histone modifications and has been shown to regulate gene expression [23-25] (Additional file 1: Fig. S1). In addition to Mbd2 or Mbd3, the NuRD complex is also composed of several other proteins: chromodomain helicase DNA-binding proteins (Chd 3, 4, and 5) which remodel chromatin; class I histone deacetylases (Hdac 1, 2, 3, and 8) that deacetylate histone tails and are associated with chromatin compaction and gene silencing; retinoblastoma-binding protein (Rbbp4/7; also known as RbAp46/48) which is a histone chaperone; GATA-binding protein (Gata2a/b); and metastasis-associated proteins (Mta1/2/3). While Mbd2/ 3 and Gata2a/b are exclusively found in the NuRD complex, the other proteins can also belong to other proteins complexes and therefore have NuRD-independent functions.

Most of what we know about DNA methylation in metazoans comes from studies conducted in a few model organisms, mainly mammals. While a handful of studies of DNA methylation in non-model organisms from various animal clades have been published recently (e.g., [26-33]), little is known about the importance and roles of $5 \mathrm{mC}$ modifications in non-vertebrate species. We therefore decided to study DNA methylation in an emerging developmental biology model system, the marine annelid worm Platynereis dumerilii. Annelids belong, together with phyla such as mollusks and platyhelminthes, to lophotrochozoans, one of the three branches of bilaterian animals, distinct from those to which vertebrates (deuterostomes), and arthropods and nematodes (ecdysozoans) belong [34]. P. dumerilii has a complex 
life cycle composed of several phases [35] starting by a three-day-long embryonic development that gives rise to small larvae with three segments bearing appendages (parapodia). These larvae then metamorphose into small juvenile worms that enter a long phase of juvenile growth during which they add additional segments one by one in the posterior part of their body (a process known as posterior growth) [36]. Posterior growth relies on the presence of a subterminal posterior growth zone that contains putative stem cells, the sustained proliferation of which allows the formation of segments over many months [36]. During this phase of juvenile growth, $P$. dumerilii worms also display substantial regenerative abilities. In particular, after posterior amputation (removal of several segments, the posterior growth zone, and the terminal body part containing the anus called the pygidium), $P$. dumerilii worms are able to regenerate the differentiated structures of the pygidium and the stem cells of the growth zone whose activity subsequently allows for the reformation of the amputated segments [37]. This process, called posterior regeneration, involves the formation of a regeneration blastema whose cells likely derive from the dedifferentiation of cells belonging to tissues abutting the amputation plane. Indeed, at 1 and 2 days post-amputation, cells at the amputation site start to express various proliferation and pluripotency stem cell markers [37], suggesting that amputation induces extensive reprogramming of differentiated cells into proliferating progenitor/stem cells.

Given the well-known importance of epigenetic modifications such as DNA methylation during cellular reprogramming events and evidence for their involvement during vertebrate regeneration (e.g., [3, 38-40]), we hypothesized that epigenetic modifications might be important during $P$. dumerilii posterior regeneration and that this process might represent a valuable model to understand how epigenetic regulation influences cellular reprogramming and regeneration. In this study, using in silico and experimental approaches, we found high levels of CpG methylation in the $P$. dumerilii genome, with significant variations during development. Using genomic data and phylogenetic analyses, we identified a full set of $P$. dumerilii writers, modifiers, and readers of $5 \mathrm{mC}$ methylation, as well as NuRD components. We subsequently studied the evolution of these proteins in animals. We also found that many of the corresponding genes have dynamic expression during development and regeneration. Strikingly, most investigated genes have expression patterns during regeneration similar to those previously documented for stem cell genes [37]. Treatments with a DNA hypomethylating drug, Decitabine (5-aza-2'-deoxycytidine), impaired larval development, regeneration, and subsequent segment addition, suggesting a requirement of DNA methylation for posterior regeneration and post-regenerative posterior growth in P. dumerilii.

\section{Results \\ High level of $\mathrm{CpG}$ methylation in $P$. dumerilii}

In a first attempt to characterize DNA methylation in $P$. dumerilii, we used a computational approach that allows to evaluate the DNA methylation level and pattern of an organism based on the determination of normalized CpG content (e.g., [41-43]). Indeed, methylated CpGs are hypermutable compared to the other dinucleotides [44]. While deamination of non-methylated cytosine can be efficiently repaired, $5 \mathrm{mC}$ deamination gives rise to thymines which are less efficiently processed by DNA repair mechanisms [44, 45]. As a consequence, the mutation rate of $5 \mathrm{mC}$ into $\mathrm{T}$ is much higher than other transitions [46]. In species with high levels of $5 \mathrm{mC}$ in $\mathrm{CpGs}$, there is an increase of the mutation rate from CpG to TpG or CpA, which leads, over several generations of germline mutation accumulation, to low contents of CpGs in the genomes of these species [47]. Determining the CpG observed/expected (o/e) ratios can thus be used to estimate $5 \mathrm{mC}$ levels: $\mathrm{CpG}$ o/e close to 1 means no methylation while CpG o/e far below 1 suggests that methylation of CpGs is present (e.g., [41-43]). As in non-vertebrates methylated CpGs are mostly found within gene bodies [11, 12], we calculated CpG o/ e for $P$. dumerilii gene bodies, by applying Notos, a software that computes $\mathrm{CpG}$ o/e ratios based on kernel density estimations $[43,48]$, on a high-quality $P$. dumerilii reference transcriptome [49]. We found a CpG o/e distribution with a single mode at 0.55 (Fig. 1a), suggesting high-level gene body methylation in P. dumerilii. Indeed, based on a large-scale analysis of 147 species from all major eukaryote lineages, four types of gene body methylation have been defined and $P$. dumerilii fits into type 3 to which belong species with high gene body methylation, which is the case for most vertebrates [48]. We used the same approach to calculate $\mathrm{CpG}$ o/e for additional species used for phylogenetic analyses of methylation machinery proteins (Additional file 2: Table S1; Additional file 3: Fig. S2)-see below for further discussion.

To further assess CpG methylation in the $P$. dumerilii genome at the experimental level, we performed genomic DNA (gDNA) digestion with the methylationsensitive enzyme HpaII and its methylation-insensitive isoschizomer MspI, which target CCGG sites [50]. If portions of genomes are methylated, different profiles of restriction fragments are expected from the two enzymatic digestions. To facilitate interpretation of profiles obtained with $P$. dumerilii gDNA, we included gDNA from species with known methylation patterns in our experiment (Fig. 1b). Drosophila melanogaster do not have 

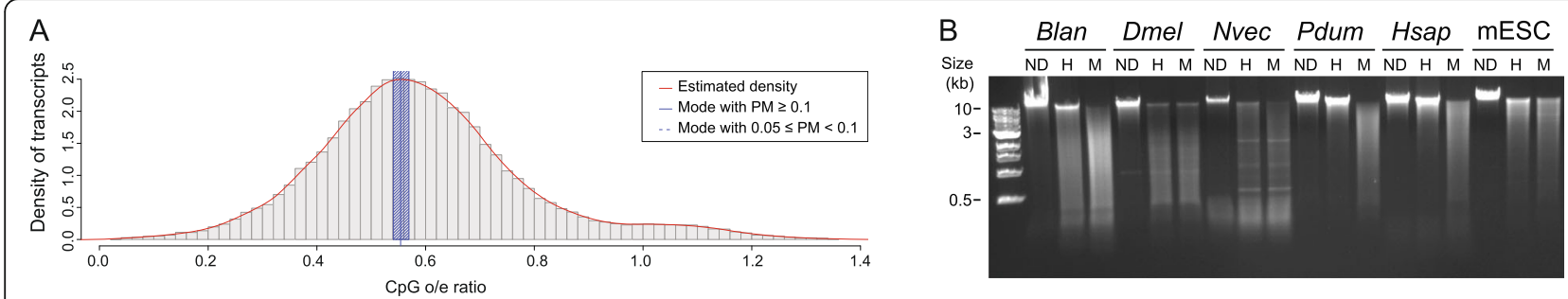

C

D

E
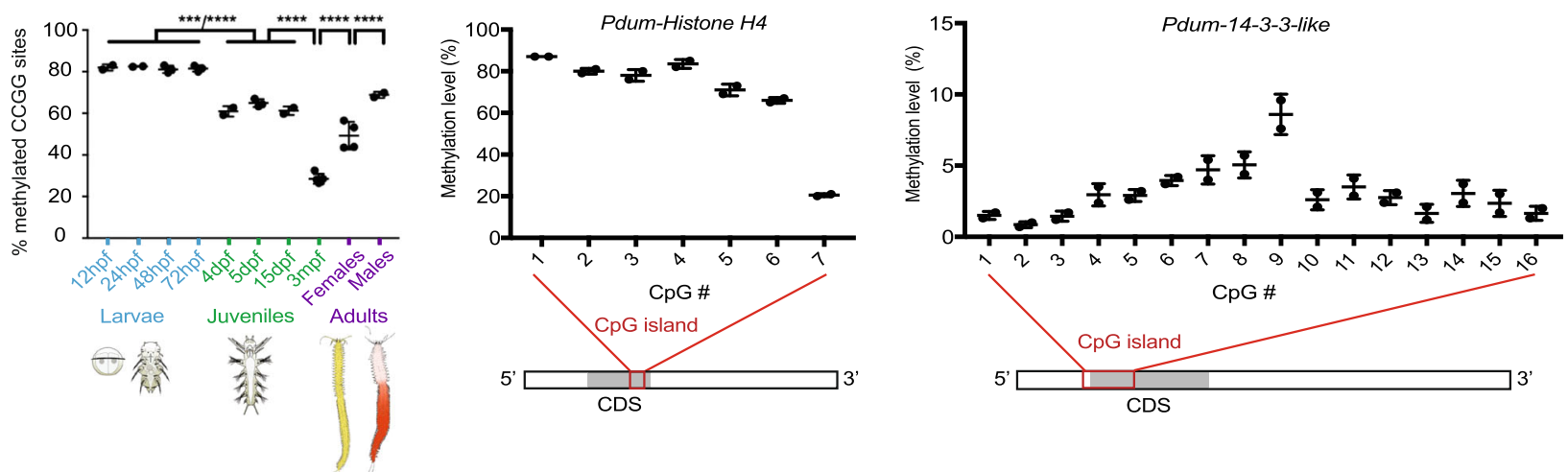

Fig. 1 High-level and gene body $C p G$ methylation in P. dumerilii. a Histogram of $C p G$ o/e ratios of $P$. dumerilii transcripts. The red line indicates the estimated density, the vertical blue bar shows estimated mean value, and the shaded blue bar represents bootstrap confidence intervals of 95\%. PM = probability mass. $\mathbf{b}$ Electrophoresis of non-digested (ND) genomic DNA (gDNA) or digested with Hpall (H) or Mspl (M) from six different animal species with different methylation types. Sizes of fragments, in kilobase pairs (kb), are indicated to the left. Abbreviations: Blan = Branchiostoma lanceolatum; Dmel = Drosophila melanogaster; Nvec = Nematostella vectensis; Pdum = Platynereis dumerilii; Hsap = Homo sapiens; mESC = Mus musculus naïve embryonic stem cells. $\mathbf{c}$ Graphic representation of DNA methylation measured by LUMA at ten different stages of $P$. dumerilii life cycle (four larval stages, four juvenile stages, and adults (male and females); at least two biological replicates per stage and at least two technical replicates per biological replicate). Mean \pm SD. One-way ANOVA, Tukey post hoc test $\left({ }^{* * * *}: p<0.0001,{ }^{* * *}: p<0.001\right)$. The raw data and results of all statistical tests can be found in Additional file 2: Table S2. $\mathrm{hpf}=$ hours post-fertilization; $\mathrm{dpf}=$ days post-fertilization; $\mathrm{mpf}=$ months post-fertilization. Drawings of larvae, juveniles, and adult worms are adapted from [35]. $\mathbf{d}, \mathbf{f}$ Graphic representation of methylation levels of stretches of CpGs (CpG island) in two P. dumerilii genes, Pdum-Histone H4 (d) and Pdum-14-3-3-like (e), as defined by bisulfite pyrosequencing on DNA extracted from $72 \mathrm{hpf} \mathrm{larvae} \mathrm{(two} \mathrm{biological} \mathrm{replicates} \mathrm{and} \mathrm{two} \mathrm{technical} \mathrm{replicates} \mathrm{per} \mathrm{biological} \mathrm{replicate).} \mathrm{Mean} \pm$ SD of two biological replicates is shown. A schematic representation of the localization of the studied CpG islands in the transcribed region of the two genes is also shown. CDS = coding sequence. Data shown in the graph and methylation levels at other developmental stages can be found in Additional file 2: Table S3

$5 \mathrm{mC}$ methylation and, as previously reported [51], similar profiles are obtained for both HpaII and MspI enzymatic digestions. The cephalochordate Branchiostoma lanceolatum and the cnidarian Nematostella vectensis have a mosaic pattern of methylation (type 4 in [48]), characterized by the presence of a large number of different cleaved fragments in both digestions and a high molecular weight fraction only found with HpaII [50]. Vertebrates such as Homo sapiens have global $\mathrm{CpG}$ methylation in their genome (type 3 in [48]), and accordingly their gDNA is largely resistant to HpaII digestion [50]. An exception are naïve mouse embryonic stem cells (mESC) [52] where similar restriction profiles with both enzymes were observed. In the case of $P$. dumerilii, we found a restriction pattern that is remarkably similar to that of $H$. sapiens, further supporting the hypothesis of high levels of CpG methylation in this species (Fig. $1 b)$.
We next performed LUminometric Methylation Assay (LUMA) $[53,54]$ to obtain a quantitative assessment of CpG methylation and information about its dynamics during Platynereis's life cycle. LUMA is an efficient method to measure global CpG methylation, based on gDNA digestion (at CCGG sites) by methylationsensitive restriction enzymes followed by pyrosequencing. LUMA was performed on $P$. dumerilii gDNA extracted from ten different stages (Fig. 1c). Very high and similar methylation levels were found during embryonic/ larval development (from 12 to $72 \mathrm{~h}$ post-fertilization, hpf; about $80 \%$ of CCGG sites are methylated; Additional file 2: Table S2). This level significantly decreases after the end of larval development, as shown in juvenile worms (early stages of post-larval growth; 4, 5, and 15 days post-fertilization, dpf), but nevertheless remains quite high (about $60-65 \%$ of methylated CCGG sites). The methylation level further decreases in older juvenile worms (3 months post-fertilization, mpf; about $27-32 \%$ ) 
and subsequently increases when worms become sexually mature, significantly more in males (about 67-70\%) than in females (about 43-56\%).

To confirm the existence of gene body methylation in P. dumerilii, we performed bisulfite pyrosequencing [55] on CpG-rich parts of the coding region of two different genes, Pdum-histone H4 and Pdum-14-3-3-like. These two genes were selected because they display stretches of CpGs in their coding region (7 and $16 \mathrm{CpGs}$ for Pdum-histone H4 and Pdum-14-3-3-like, respectively). Additionally, orthologs of these genes in other lophotrochozoan species were shown to have gene body methylation [28, 30]. Using DNA extracted from 72hpf larvae, we found high levels of methylation (between 65 and 87\%) for 6 of the 7 CpGs of Pdum-histone H4, and low levels for all CpGs of Pdum-14-3-3-like (<10\%; Fig. 1d). These data therefore indicate that gene body methylation does indeed occur in $P$. dumerilii and that the level of methylation strongly differs in the two studied genes. In contrast, the level of methylation in the coding region of these two genes remains almost constant throughout the life cycle of the worm, as shown by bisulfite pyrosequencing using DNA extracted from five additional stages (Additional file 2: Table S3).

Taken together, these data indicate high-level CpG methylation in the $P$. dumerilii genome. In addition, the $5 \mathrm{mC}$ level is dynamic along the $P$. dumerilii life cycle and is significantly higher during embryonic/larval development as compared to post-larval stages. Striking changes in methylation level also occur during postlarval growth and when the worms reach sexual maturity. We also obtained evidence for gene body methylation in $P$. dumerilii and found that the level of $\mathrm{CpG}$ methylation in gene bodies is not uniform from one gene to another.

\section{P. dumerilii possesses a full ancestral-like DNA methylation and NuRD toolkit}

Having established the existence of $5 \mathrm{mC}$ in P. dumerilii, we next aimed to identify proteins involved in writing, modifying, and reading this epigenetic mark, as well as putative NuRD components, in this species. For that purpose, we searched for $P$. dumerilii orthologs of proteins known to exert these functions in mammals (Additional file 1: Fig. S1) through a sequence-similarity approach using reciprocal best BLAST with Homo sapiens and Mus musculus sequences as queries. We found putative $P$. dumerilii orthologs for all investigated proteins/protein families (Additional file 4: Fig. S3). Sequences of all the identified proteins can be found in Additional File 5. As $5 \mathrm{mC}$ and NuRD proteins are often characterized by the presence of particular domains or association of domains, we searched for conserved domains present in the retrieved $P$. dumerilii proteins. In most cases, we found domains that are consistent with orthology relationships inferred from BLAST analyses (Additional file 4: Fig. S3).

Since defining orthology relationships only on BLAST analyses can be misleading, in particular when numerous paralogs are present, we turned to phylogenetic analyses to ascertain these relationships. To perform these analyses on a firm basis and to get insight into the evolution of the DNA methylation and NuRD toolkit in animals, we retrieved, by reciprocal BLAST searches using mouse and human sequences as queries, putative orthologs from 51 additional species from diverse animal phylogenetic groups. We ended up with a sample of 54 species from all major animal lineages (Fig. 2). Maximum likelihood (ML) trees were constructed for each protein family and are shown in Additional file 6: Fig. S4. We also searched for members of the different families in species from choanoflagellates, the sister group to animals, and used, when possible, these sequences as outgroups to root the phylogenetic trees. These phylogenetic trees allow us to confirm orthology relationships for all $P$. dumerilii proteins and to define the number of members of all protein families in the 54 investigated animal species (Fig. 2). We summarized the number of members for each defined family and, based on parsimony, we inferred the presence or absence of each protein family in the last common ancestors of animals and bilaterians (Fig. 3). All the identified proteins are listed in Additional file 2: Table S4 and their sequence can be found in Additional file 5 .

The $P$. dumerilii genome encodes three Dnmt proteins that can be clearly assigned to the Dnmt 1,2 , and 3 subclasses (Additional file 6: Fig. S4A). The presence of these three subfamilies appears to be ancestral to animals (Fig. 3), as these three subfamilies are found in most non-bilaterians and in many species in the three bilaterian evolutionary lineages (Fig. 2). While only $d n m t 2$ genes were found in choanoflagellates, dnmt1 and dnmt3 genes have been reported in other eukaryotic groups, suggesting an early diversification of the Dnmt family during the evolution of eukaryotes [9]. Only a few gene duplications occurred for dnmt1 (in particular in some arthropod species) and for dnmt3 (in particular during vertebrate evolution in agreement with published studies; e.g., [56]). dnmt gene losses occurred in some species or lineages such as nematodes, rotifers, tardigrades, placozoans, and platyhelminthes. Absence of both dnmt 1 and dnmt 3 is correlated to the absence or very low abundance of cytosine DNA methylation as shown by $\mathrm{CpG}$ o/e ratio calculation (Fig. 2). P. dumerilii also possesses single tet, $t d g$, and $u h r f$ genes, which likely corresponds to the ancestral situation in animals (Figs. 2 and 3; Additional file 6: Fig. S4B-D). Duplications of tet genes are infrequent, but two duplications nevertheless 


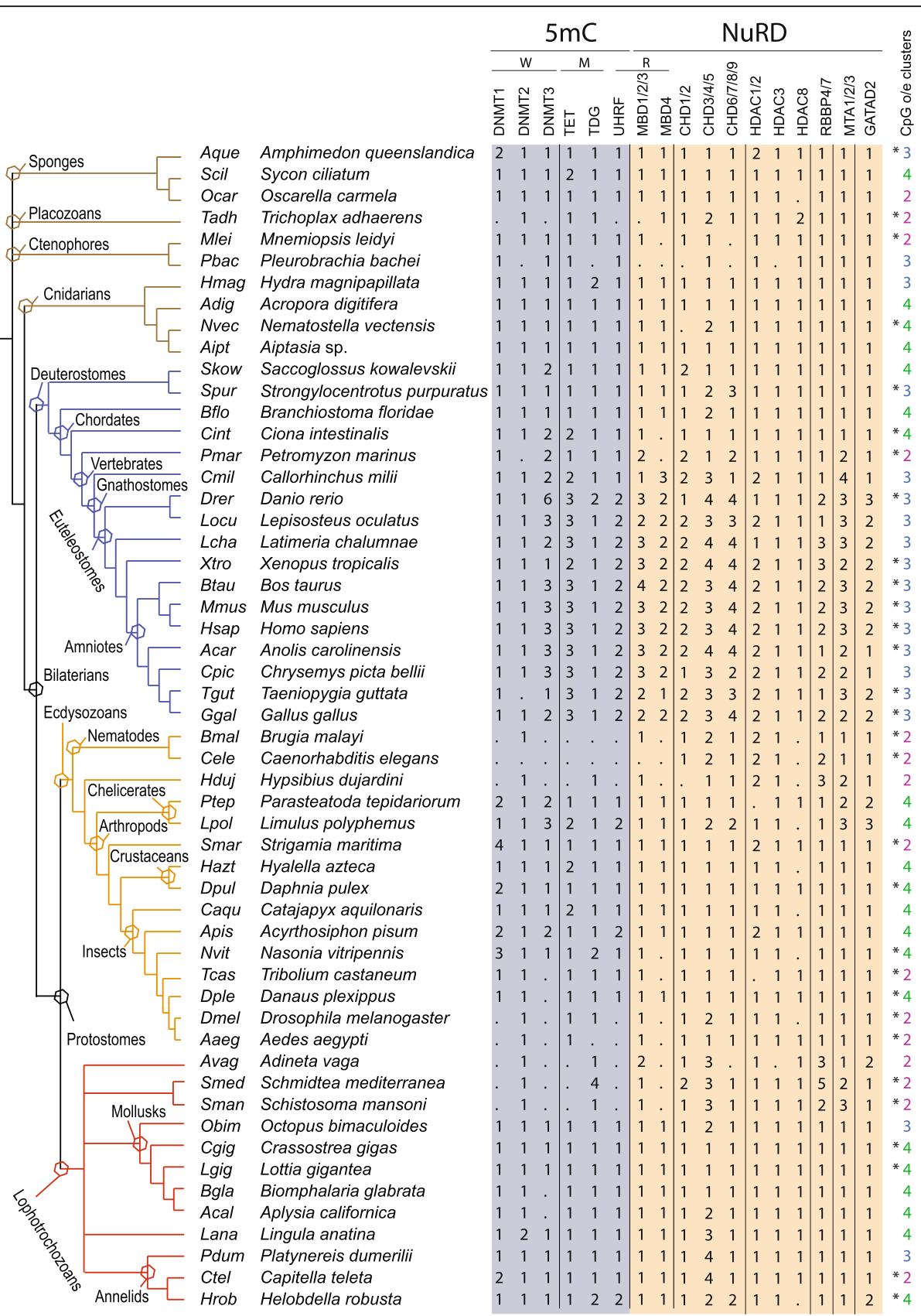

Fig. 2 DNA methylation and NuRD toolkit in metazoans. On the left is shown a phylogenetic tree of the 54 metazoan species for which we identified DNA methylation and NuRD genes. Branches of this phylogenetic tree are color-coded (brown for non-bilaterians, blue for deuterostomes, orange for ecdysozoans, and red for lophotrochozoans). Polytomies highlight uncertainties about the relationships between bilaterian and non-bilaterian groups and within lophotrochozoans. Major phylogenetic groups are shown by hexagons placed on the tree nodes defining these groups. Additional taxonomic information: Saccoglossus kowalevskii belongs to hemichordates, Strongylocentrotus purpuratus to echinoderms, Branchiostoma floridae to cephalochordates, Ciona intestinalis to urochordates, Hypsibius dujardini to tardigrades, Adineta vaga to rotifers, Schmidtea mediterranea and Schistosoma mansoni to platyhelminthes, and Lingula anatina to brachiopods. The number of members found for each gene family is indicated for each species. Dots indicate that we failed to identify any members. Chd1/2, Chd6/7/8/9, and Mbd4 gene families which do not encode NuRD members are also indicated. For each species, the type of methylation (from 1 to 4 ) inferred from CpG o/e clustering [48] is also shown (asterisks indicate data derived from a previous study [48]). Type 1 corresponds to ultra-low gene body methylation, type 2 to low gene body methylation, type 3 to gene body methylation, and type 4 to mosaic DNA methylation (see [48] for details). $W=$ Writers, $M=$ Modifiers, $R=$ Readers. Sequences of the identified proteins, multiple alignments, and phylogenetic trees can be found in Additional file 5 and Additional file 6: Figure $\$ 4$ 


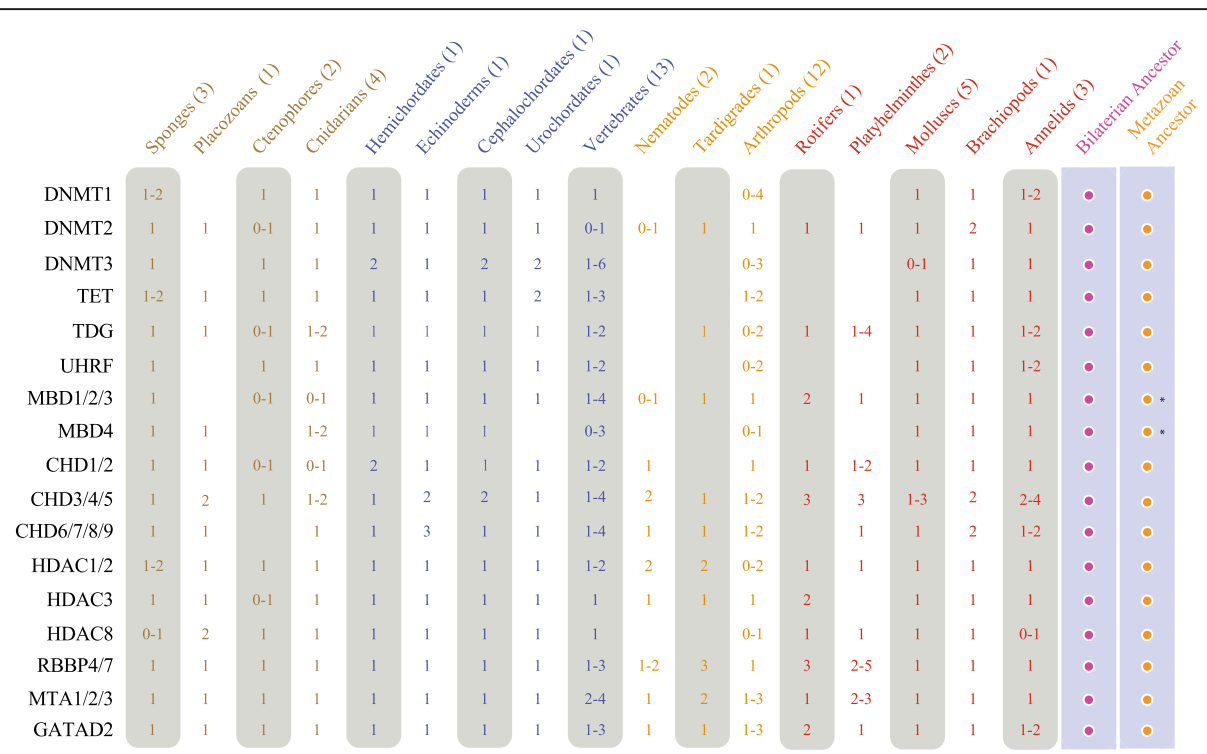

Fig. 3 Evolution of DNA methylation and NuRD gene families in metazoans. The number (or range of numbers) of members of each family/ subfamily in the indicated phylogenetic groups is shown (none if no members are detected). The number of studied species in each phylogenetic group is indicated next to the group name. Two final columns summarize the putative ancestral set of all studied families/ subfamilies in the last common ancestors of metazoans and bilaterians. The putative ancestral set of families/subfamilies in the last common ancestor of eumetazoans (cnidarians + bilaterians) is the same as the one for the bilaterian ancestor and is not shown for sake of clarity. Asterisks highlight the fact that the inference of the presence of MBD1/2/3 and MBD4 families in the metazoan last common ancestor depends on whether we consider sponges as the sister group to all other animals. If ctenophores are considered as the sister group of all other animals, it is possible that only one Mbd gene (probably from the MBD1/2/3 subfamily) was present in the last common ancestor of all animals

occurred in vertebrates [56]. tet genes are only absent in species that lack $5 \mathrm{mC}$ methylation and dnmt1 and $d n m t 3$, with the exception of dipterans which possess one tet gene. $t d g$ is present in almost all investigated species in one copy, as expected for a gene involved in DNA repair. uhrf has a similar distribution to tet, being absent in species lacking $5 \mathrm{mC}$, but in this case including dipterans. A single uhrf gene is found in most other species, with the notable exception of euteleostomes (bony vertebrates) that possess two genes (Fig. 2).

Phylogenetic analysis shows the existence of two large groups of $\mathrm{Mbd}$ proteins, one which contains Mbd1, Mbd2, and Mbd3 proteins from vertebrates (hereafter named $\mathrm{Mbd} 1 / 2 / 3$ group) and the other which contains vertebrate Mbd4 and MeCP2 proteins (Mbd4 group; Additional file 6: Fig. S4E). P. dumerilii's genome encodes two Mbd proteins, one belonging to the $\mathrm{Mbd} 1 / 2 / 3$ group (putative NuRD component) and the other to the Mbd4 group. Presence of both $\mathrm{Mbd} 1 / 2 / 3$ and $\mathrm{Mbd} 4$ is observed in many species belonging to most animal lineages, including non-bilaterians such as sponges and cnidarians, strongly suggesting that the last common ancestor of animals possessed at least two $m b d$ genes (Fig. 3). mbd gene losses occurred in few species, mainly in those that also lack cytosine DNA methylation. A few gene duplications also occurred, in particular in vertebrates in which both $m b d 1 / 2 / 3$ and $m b d 4$ ancestral genes underwent gene duplications.

The phylogenetic tree of Chd proteins comprises three large groups: one that includes vertebrate Chd3/4/5 proteins (hereafter named Chd3/4/5 group), the second vertebrate Chd1/2 (Chd1/2 group), and the third vertebrate Chd6/7/8/9 (Chd6/7/8/9 group; Additional file 6: Fig. S4F). Six chd genes have been found in $P$. dumerilii, one belonging to the Chd $1 / 2$ group, one to the Chd6/7/8/9 group, and four to the Chd3/4/5 group (putative NuRD components). Members of these three groups are found in almost all studied species, including non-bilaterians, indicating that presence of three different types of CHD proteins is ancestral to animals (Fig. 3). Only very few gene losses occurred. Gene duplications are more frequent, in particular in vertebrates and lophotrochozoans, including in annelids in which two to four members are found in the three studied species (Fig. 3).

Previous phylogenetic studies classified Hdac proteins into four classes (I, IIA/B, III, and IV) $[57,58]$. Here we focused on class I to which belong Hdac1, Hdac2, $H d a c 3$, and Hdac8, genes that encode members of the NuRD complex. Phylogenetic analysis showed the existence of three subgroups, Hdac1/2, Hdac3, and Hdac8 (Additional file 6: Fig. S4G). We found one member of each subgroup in $P$. dumerilii, as well as in almost all other investigated species, indicating that at least three 
class I hdac genes were present in the last common ancestor of all animals (Fig. 3). We found only very few gene losses (e.g., in nematodes). Duplications mainly occurred in arthropods and vertebrates. Single rbbp4/7, $m$ ta1/2/3, and gatad 2 genes are found in $P$. dumerilii (Additional file 6: Fig. S4H-J). At least one member of each of these subfamilies is found in all studied species, indicating that their presence is ancestral to animals (Fig. 3). Gene duplications occurred in vertebrates, ecdysozoans, and lophotrochozoans.

In conclusion, we have identified in $P$. dumerilii a complete set of writers, modifiers, and readers involved in $5 \mathrm{mC}$ methylation, as well as putative NuRD components. We additionally provide an animal-wide view of the evolution of the corresponding gene families (Fig. 2), which suggests that the last common ancestor of animals already possessed a complex repertoire of $5 \mathrm{mC}$ and NuRD toolkit genes (Fig. 3). Our analysis also indicates that the $P$. dumerilii repertoire is mostly composed of single-copy genes and likely close to the one present in the last common ancestor of bilaterians.

\section{DNA methylation and NuRD toolkit genes are dynamically expressed during development and regeneration in $P$. dumerilii}

We next aimed to characterize the expression of DNA methylation and NuRD genes in P. dumerilii. We first took advantage of two previously published transcriptomic datasets corresponding to various developmental stages and adult conditions of $P$. dumerilii, available in a public database (PdumBase) [59]. The first dataset corresponds to embryonic developmental stages, ranging from 2 to $14 \mathrm{hpf}$, with a time point every $2 \mathrm{~h}$ [49]. The second dataset comprises major larval stages (24 to $4 \mathrm{dpf}$; five time points), juvenile stages (10dpf to $3 \mathrm{mpf}$; five time points), and adult reproductive stages (males and females) [60]. Altogether, expression data for a total of 19 stages during embryonic and post-embryonic development, as well as male and female adult stages, are available.

Expression values for most genes (exceptions are Pdum-dnmt3 absent in the two sets of transcriptomic data and Pdum-gatad 2 and Pdum-rbbp4/7 only found as chimeric transcripts) were recovered and can be found in Additional file 7: Fig. S5. High transcript levels are found for many studied genes in the earliest developmental stages (2-6hpf) and several of them belong to co-expression clusters defined by Chou et al. [49] as maternal gene clusters (clusters 1-4; Additional file 7: Fig. S5). This indicates that the $P$. dumerilii egg contains a large pool of maternal transcripts coding for DNA methylation proteins that could be used for embryonic development. To further analyze these expression data, we studied changes in expression during the main steps of $P$. dumerilii life cycle (Fig. 4). From $2 \mathrm{hpf}$ to $14 \mathrm{hpf}$, a decrease in quantity of transcripts of about half of the genes, including genes coding for DNA methylation maintenance (Pdum-dnmt1 and Pdum-uhrf), as well as putative members of the NuRD complex (Pdum-chd3/4/ $5 A-B$ and Pdum-hdac8), is observed. From 24hpf to $4 \mathrm{dpf}$, this decrease is found for most genes, including Pdum-dnmt1 and Pdum-uhrf. In contrast, expression of Pdum-tet and Pdum-tdg is increased or stable, respectively. This is consistent with the decrease of the CCGG methylation level that we observed at the end of larval development (Fig. 1c). From $4 d p f$ to $3 \mathrm{mpf}$, a majority of genes have stable expression with the exception of the upregulation of every chd gene except $c h d 3 / 4 / 5 B$, which is downregulated (Fig. 4). Transition from $3 \mathrm{mpf}$ to the adult stage is strikingly gender-specific: in males, most genes have stable or downregulated expression, while about $80 \%$ of the genes are strongly upregulated in females (Fig. 4; Additional file 7: Fig. S5), suggesting different occurrence and importance of DNA methylation during sexual maturation and gamete production between males and females.

We next studied the expression of DNA methylation and NuRD genes during $P$. dumerilii posterior regeneration. To characterize in which part(s) and tissue(s) of the regenerated region these genes are expressed, we performed whole-mount RNA in situ hybridizations (WMISH) at all five stages of posterior regeneration (a schematic representation of regeneration stages can be found in Additional file 8: Fig. S6) [37], focusing on a set of ten genes that encode putative writers/modifiers/readers of $5 \mathrm{mC}$ or $\mathrm{NuRD}$ components. Representative expression patterns are shown in Fig. 5 and Additional file 9: Fig. S7. A schematic representation of the expression patterns can be found in Additional file 10: Fig. S8. We also tried to define the expression of the studied genes in nonamputated worms (to compare to the expression during regeneration) but failed to obtain any signal above the background level with our WMISH protocol, likely due to the presence of a thick cuticle around the fully differentiated segments of these worms [36]. As a proxy of non-amputated worms, we therefore used worms that have regenerated for 15 days (15 days post-amputation, dpa) and which show many welldifferentiated segments lacking the thick cuticle that hampers WMISH in non-amputated worms. Representative expression patterns of the studied genes in these worms are shown in Additional file 11: Fig. S9. We were also able to detect the expression of some genes in worms fixed immediately after amputation (hereafter named stage 0 ), as the wound probably favors the penetration of the probes used for WMISH. Only very weak expression was however observed for 


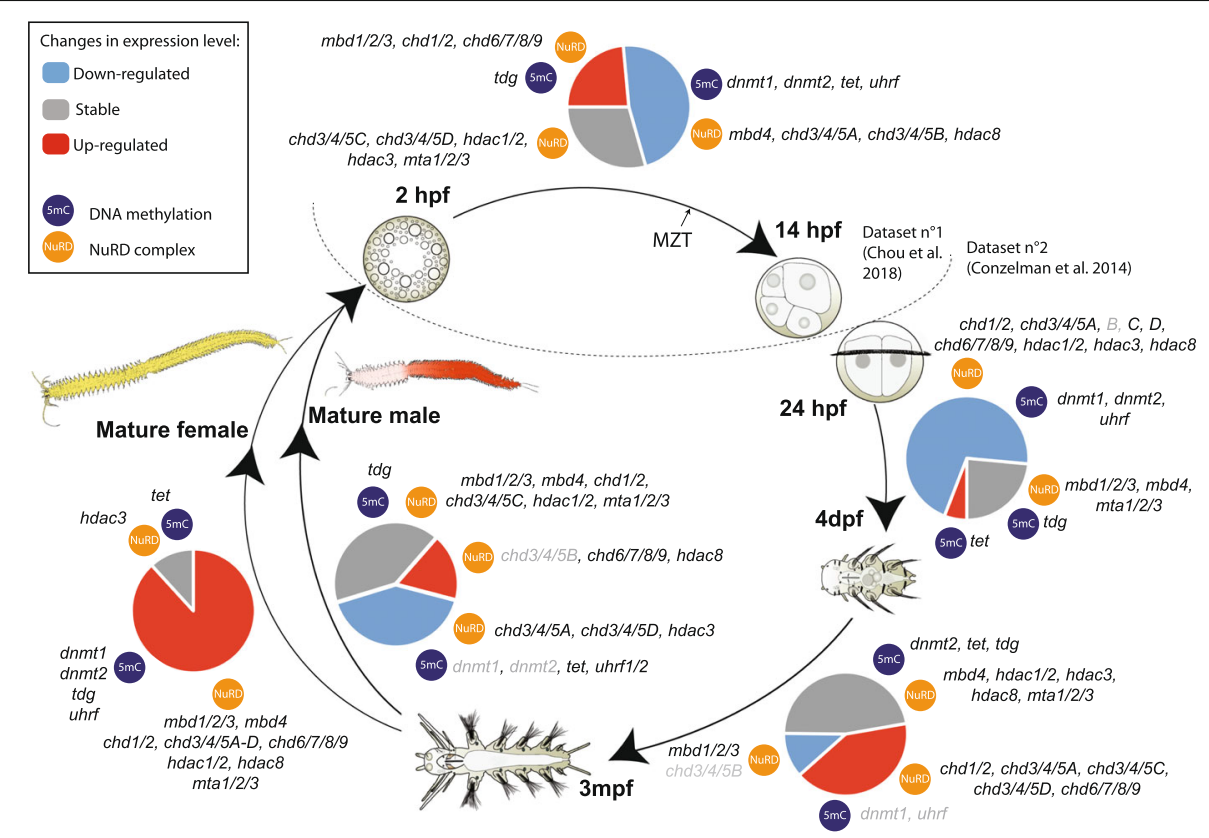

Fig. 4 DNA methylation and NuRD genes are dynamically expressed during the $P$. dumerilii life cycle. The main steps of $P$. dumerilii life cycle are shown. Expression changes between consecutive stages are indicated as "downregulated" (expression level decreases with a fold change superior to two), "stable" (fold change inferior to two), and "upregulated" (expression level increases with a fold change superior to two). Proportions of these three categories are represented as color pie charts. Genes encoding $5 \mathrm{mC}$ toolkit and NuRD/NuRD-related proteins are mentioned. Gray letterings indicate genes with low expression ( $<5$ fragments per kilobase million, FPKM) in the compared stages. The two datasets that have been used are indicated $[49,60]$. Maternal to zygotic transition (MZT) is shown at around 10hpf as previously suggested [49]. hpf $=$ hours postfertilization, $\mathrm{dpf}=$ days post-fertilization, $\mathrm{mpf}=$ months post-fertilization. For sake of clarity, Pdum- prefixes have been omitted for the gene names. Drawings of embryos, larvae, juvenile, and adult worms are adapted from [35]. Expression values for all the genes shown in this figure can be found in Additional file 7: Fig. S5

most studied genes in stage 0 worms (Additional file 12: Fig. S10), and these expressions will not be further discussed.

Pdum-dnmt1 and Pdum-dnmt3 are weakly expressed in the wound epithelium at stage 1 (Fig. 5a1, b1). At stage 2, Pdum-dnmt1 is strongly expressed in two internal groups of cells and in the lateral ectoderm (Fig. $5 \mathrm{a} 2$ ). Its expression extends in almost the whole blastema at stage 3 and is found in the regenerated growth zone (Fig. 5a3). At the same stages, Pdum-dnmt3 is very weakly expressed in both mesodermal and ectodermal cells of the regenerated region (Fig. 5b2, b3). At stages 4 and 5, Pdum-dnmt1 is expressed in the mesoderm of the developing segments, mesodermal and ectodermal growth zone, at the base of the anal cirri, and weakly in the lateral/dorsal ectoderm (Fig. 5a4, a5; Additional file 9: Fig. S7A). Pdum-dnmt3 is expressed in the ventral ectoderm and at the base of the anal cirri (Fig. 5b4, b5). Broad and diffuse expression in the developing segments was observed for both genes in worms at 15dpa (Additional file 11: Fig. S9A, B). Pdum-tet expression is not reliably detected at stage 1 (Fig. $5 \mathrm{c} 1$ ). At stages 2 and 3 , a weak expression is found in both internal and superficial blastemal cells (Fig. 5c2, c3), which continues at stages 4 and 5 and at which expression is also observed at the base of anal cirri (Fig. 5c4, c5). At 15dpa, Pdumtet expression is found in both the mesoderm and ectoderm of the developing segments (Additional file 11: Fig. S9C). Pdum-tdg is strongly expressed at stage 1 in the wound epithelium and internal cells of the segment abutting the amputation plane (Fig. $5 \mathrm{~d} 1$ ). At stages 2 and 3 , it is broadly expressed in the whole blastema (Fig. $5 \mathrm{~d} 2$, d3). From stage 3, Pdum-tdg is expressed in mesoderm and ectoderm of the developing segments, and in ectodermal and mesodermal growth zones, as well as weakly at the base of the anal cirri (Fig. 5d4, d5; Additional file 9: Fig. S7B). Pdum-tdg is expressed in the ventral ectoderm and in the developing parapodia at 15dpa (Additional file 11: Fig. S9D).

Pdum-mbd1/2/3, Pdum-hdac3, and Pdum-hdac8 have roughly similar expression during posterior regeneration, Pdum-hdac3 being expressed at most stages weaker than the two other genes. At stage 1 , an expression is detected in two lateral patches of cells in and close to the wound epithelium (Fig. 5e1, f1, g1). The three genes are widely expressed in the blastema at stages 2 and 3 (Fig. 5e2, e3, f2, f3, g2, g3). Expression in the mesoderm and ectoderm of the developing segments, growth zone, and 


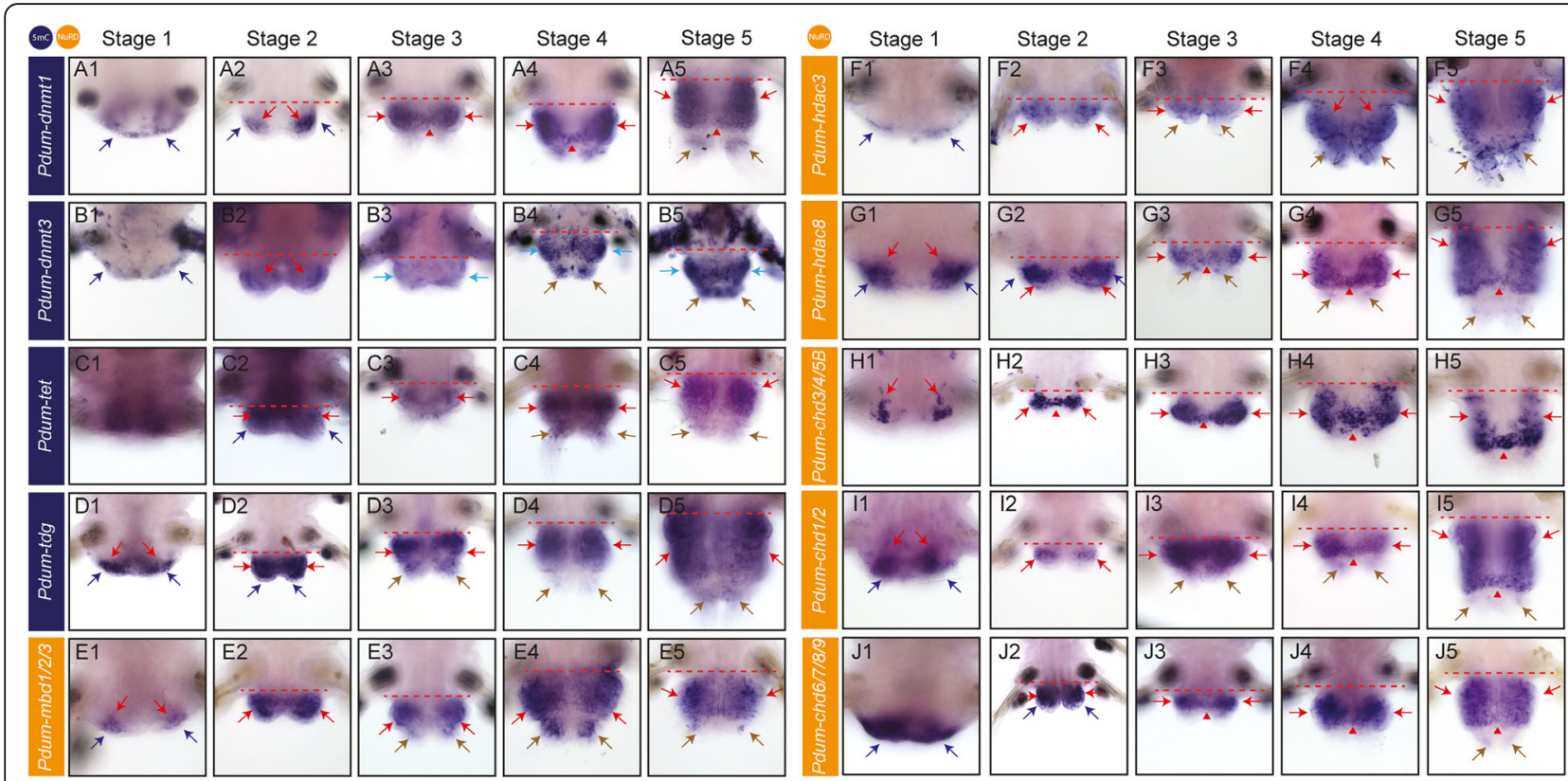

Fig. 5 DNA methylation and NuRD genes are expressed during most or all stages of $P$. dumerilii regeneration. Expression patterns obtained by whole-mount in situ hybridization (WMISH) for genes whose name is indicated at the five previously defined stages of posterior regeneration [37] are shown. All panels are ventral views (anterior is up). Red dotted lines indicate the amputation plane in worms at stages 2 to 5, delineating the regenerated region (below the dotted lines) from the segment abutting the amputation plane (above the dotted lines). At stage 1, only a wound epithelium has already formed (dark blue arrows) and red arrows point to internal cells of the segment adjacent to the amputation. At the other stages, dark blue arrows point to epithelium covering the blastema, red arrows point to mesodermal cells of the blastema or developing segments (depending on stages), red arrowheads to the mesodermal part of the growth zone, light blue arrows to ectodermal expression, including segmental ectodermal stripes, and brown arrows to the base of anal cirri. Additional expression patterns are shown in Additional file 9: Fig. S7, Additional file 11: Fig. S9, and Additional file 12: Fig. S10

at the base of the anal cirri is observed at stages 4 and 5 (Fig. 5e4, e5, f4, f5, g4, g5; Additional file 9: Fig. S7C, D). Broad and diffuse expression patterns in the developing segments were observed for the three genes at $15 \mathrm{dpa}$ (Additional file 11: Fig. S9E-G). Pdum-chd3/4/5B expression is found at stage 1 in four small patches of internal cells close (but not adjacent) to the wound epithelium, two located ventrally and two dorsally (Fig. 5h1; Additional file 9: Fig. S7E). From 2dpa, we observed an intense expression in the mesodermal part of the regenerated region, including the mesodermal growth zone (Fig. 5h2-h5; Additional file 11: Fig. S9H). Pdumchd1/2 and chd6/7/8/9 are expressed in cells in and close to the wound epithelium at stage 1, the latter having a much broader expression (Fig. 5i1, j1). At stage 2, both genes are expressed in superficial and internal cells of the regenerated region, in most or all cells for Pdumchd6/7/8/9 but only in a few cells for Pdum-chd1/2 (Fig. $5 i 2, j 2)$. Broad expression in mesodermal cells, including the growth zone, is observed at later stages (Fig. 5i3-i5, j3-j5). At stage 5, Pdum-chd $1 / 2$ is also weakly expressed in the ectodermal growth zone (Additional file 9: Fig. S7F). At 15dpa, Pdum-chd6/7/8/9 is weakly expressed in the developing segments (Additional file 11: Fig. S9I).
We failed to detect significant expression of Pdum-chd1/ 2 at $15 \mathrm{dpa}$.

Altogether, we found that $P$. dumerilii DNA methylation and NuRD genes are dynamically expressed during embryonic, larval, and post-larval development, as well as during sexual maturation and regeneration. During this latter process, most genes are expressed from its earliest stages and their expression is later mostly found in blastemal cells, putative mesodermal and ectodermal stem cells of the growth zone, and cells of the developing segments (Additional file 10: Fig. S8). Observed patterns of expression show striking similarities with those previously reported for proliferation $(c y c B$ and pcna genes) and stem cell genes (e.g., piwi, vasa, nanos, and myc genes) [37], suggesting that DNA methylation and NuRD genes are mainly expressed in undifferentiated proliferating cells, including stem cells of the regenerated posterior growth zone.

\section{Decitabine reduces DNA methylation and impairs development, regeneration, and post-regenerative posterior growth in $P$. dumerilii}

To test a possible role of DNA methylation during $P$. dumerilii regeneration, we tried to reduce $5 \mathrm{mC}$ levels 
using two well-known and widely used hypomethylating agents: Decitabine (5-aza-2'-deoxycytidine) and RG108 (N-Phthalyl-L-Tryptophan) [61-63]. Decitabine is incorporated in DNA and binds Dnmt1 irreversibly, leading to a progressive loss of DNA methylation through cell divisions. RG108 is a specific non-nucleoside inhibitor of Dnmt1, which acts by binding in a reversible manner to the active center of the enzyme. As these two drugs have never been used in P. dumerilii, we first tested their activity by treating larvae continuously from 1 to $3 \mathrm{dpf}$ with Decitabine or RG108 (Fig. 6a). Neither drugs caused significant lethality during treatment. DNA was extracted from larvae at 3dpf and CCGG methylation level measured using LUMA (Fig. 6b): Decitabine treatment leads to a 2.5 -fold decrease of CCGG methylation (from 81.5 to $32.4 \%$ ) while no significant effects were found for RG108. We also checked for morphological defects (Fig. 6c): larvae were observed either immediately after treatment (at 3dpf) or after washing out the drug and putting larvae in normal sea water until 5 or 14dpf. Larvae that had been treated with Decitabine presented morphological abnormalities at 3dpf, in particular reduced parapodia (worm appendages) bearing very few chaetae (extracellular chitinous structures) and a reduced pygidium (Fig. 6c). While abnormal, these larvae were alive and survived for a few more days. All animals did however die in the following days, possibly because of feeding defect (during this period normal young worms start to eat, dead Decitabine-treated worms consistently showed an empty gut). In contrast, RG108 treatment did not affect larval morphology (Fig. 6c). We therefore conclude that Decitabine can affect DNA methylation levels and larval development in $P$. dumerilii.

To investigate potential consequences of a decrease of DNA methylation on regeneration, we treated worms with three concentrations of Decitabine $(10 \mu \mathrm{M}, 50 \mu \mathrm{M}$, and $100 \mu \mathrm{M})$ immediately after amputation for 5 days and scored the worms every day for the stage that had been reached based on a previously established staging system (Additional file 8: Fig. S6) [37]. We found a small number of deaths at $10 \mu \mathrm{M}$ and $50 \mu \mathrm{M}$ concentrations, while a $100 \mu \mathrm{M}$ concentration appears to be much more harmful to worms (Additional file 2: Table S5). Some worms also underwent spontaneous amputation of their posterior part (autotomy) at some time points (Additional file 2: Table S5). These worms were excluded from the analysis. We found that Decitabine significantly delayed regeneration as compared to controls (DMSO $0.5 \%$ and sea water), in a concentration-dependent manner (Fig. 7a). At 5 days post-amputation (dpa), while most control worms reached stage 4 or more, worms treated with Decitabine were mostly at stages 2 to 3 (Fig. $7 \mathrm{~b}$ ). No major abnormalities were observed at the morphological level in Decitabine-treated worms (not shown). To better understand how regeneration proceeds in the presence of Decitabine, we did Decitabine treatments (at $50 \mu \mathrm{M}$ as this concentration shows low toxicity and pronounced effect on regeneration) from $0 \mathrm{dpa}$ to $5 \mathrm{dpa}$, fixed treated worms at $5 \mathrm{dpa}$, and performed WMISH for some of the genes whose expression was previously studied during normal regeneration [37]. The analyzed genes showed expression at $5 \mathrm{dpa}$ in Decitabine-treated worms that are similar to those of stage 2 or 3 in non-treated worms [37], indicating that regeneration is blocked in the presence of Decitabine (Fig. 7c). Abnormal expression patterns, never observed in non-treated animals, were nevertheless found in some treated worms for Pdum-hox3 (growth zone marker; extended and/or mis-located expression domain), PdumpiwiB (stem cell marker; no or reduced expression), and Pdum-engrailed (segment marker; incomplete expression stripes).

It has been shown that mammalian cells treated with Decitabine only partially recover their initial methylation level, leading to an epigenetic "imprint" of drug exposure [64]. We hypothesized that Decitabine treatment could have long-term impacts in $P$. dumerilii and affect segment formation that follows regeneration (post-regenerative posterior growth $[36,37])$. To test this hypothesis, we treated worms with Decitabine from 0 to $5 \mathrm{dpa}$, then washed out the drug, put worms in normal sea water until $25 \mathrm{dpa}$, checking their morphology and counting the number of segments that have been produced at six time points (Fig. 8a). As for the previous experiment, Decitabine treatments induced few worm deaths and autotomies (Additional file 2: Table S6). Most Decitabine worms recovered from the treatment and were able to reach stage 5 and undergo posterior growth (Fig. 8b). Decitabine-treated worms continued to be delayed as compared to control worms, had a reduced number of newly added segments at 25dpa (treated worms had about 4 to 6 segments compared to about 10 to 12 segments for controls), and showed morphological abnormalities (Fig. 8b, c). A reduced number of newly added segments was due not only to a marked delay during regeneration, but also to a reduced rate of segment addition after the drug had been washed out (Additional file 13: Fig. S11A). A high variability was observed among Decitabine-treated animals compared to controls (Additional file 13: Fig. S11B-F). We defined three classes of animals based on their morphology and the number of newly added segments at 25dpa (Fig. 8c; Additional file 14: Fig. S12). Class 1 animals (30.6\% of Decitabine-treated worms) show a characteristic bottleneck-like shape with a marked constriction between non-regenerated and regenerated regions, no or few newly added segments, and no or abnormal anal cirri. These worms are prone to undergo autotomy. 

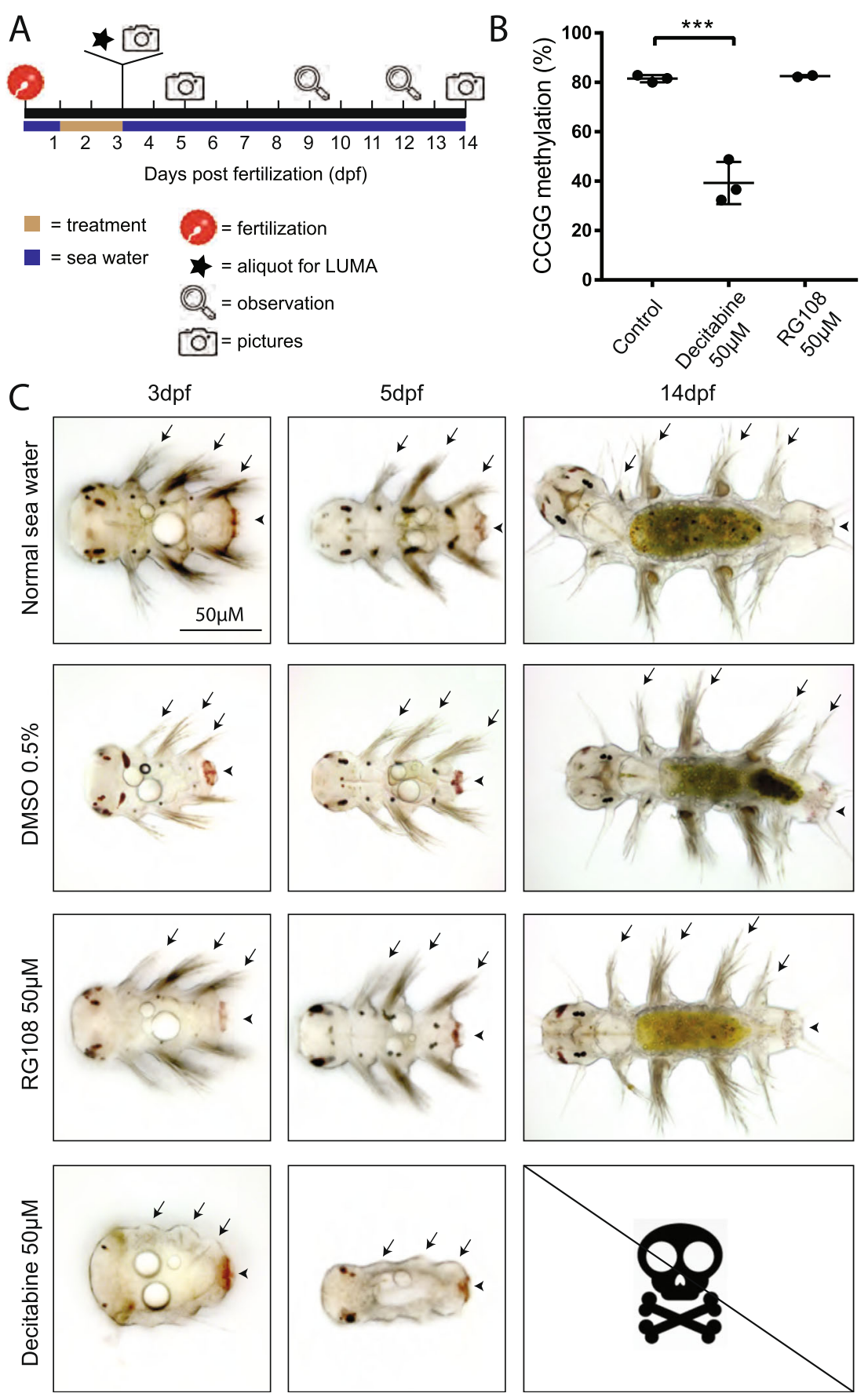

Fig. 6 Decitabine treatment decreases DNA methylation level and impairs larval development. a Schematic representation of the experimental design. Larvae were treated with Decitabine $(50 \mu \mathrm{M})$, RG108 $(50 \mu \mathrm{M})$, or DMSO (0.5\%; control) from 1 day post-fertilization (1dpf) to $3 \mathrm{dpf}$. At $3 \mathrm{dpf}$, a part of the batch of larvae was frozen for subsequent DNA methylation measurement with LUMA and remaining larvae were placed and kept in normal sea water until 14dpf. Observations were done at indicated time points and pictures taken at 3, 5, and 14dpf. b Graphic representation of CCGG DNA methylation as measured by LUMA for the different conditions (two or three biological replicates per condition and two technical replicates per biological replicate). Mean \pm SD. One-way ANOVA, Dunnet post hoc test was performed (***: $p<0.001)$. The raw data can be found in Additional file 2: Table S2. c Morphological observations at 3, 5, and 14dpf. Ventral views of representative larvae/juvenile worms are shown (anterior on the left). At the three time points, RG108-treated larvae/juvenile worms show morphologies similar to those of controls (sea water and DMSO 0.5\%). At 14dpf, like the control animals, RG108-treated worms have added a fourth segment. In contrast, at 3 and $5 \mathrm{dpf}$ Decitabine-treated larvae/juvenile worms display an abnormal morphology with strongly reduced appendages (parapodia; arrows) and a reduced pygidium (arrowheads). Massive death occurred in the 5 to $9 \mathrm{dpf}$ time period, so no Decitabine-treated worms could be observed at $14 \mathrm{dpf}$. These experiments were performed twice using larvae from independent fertilizations 


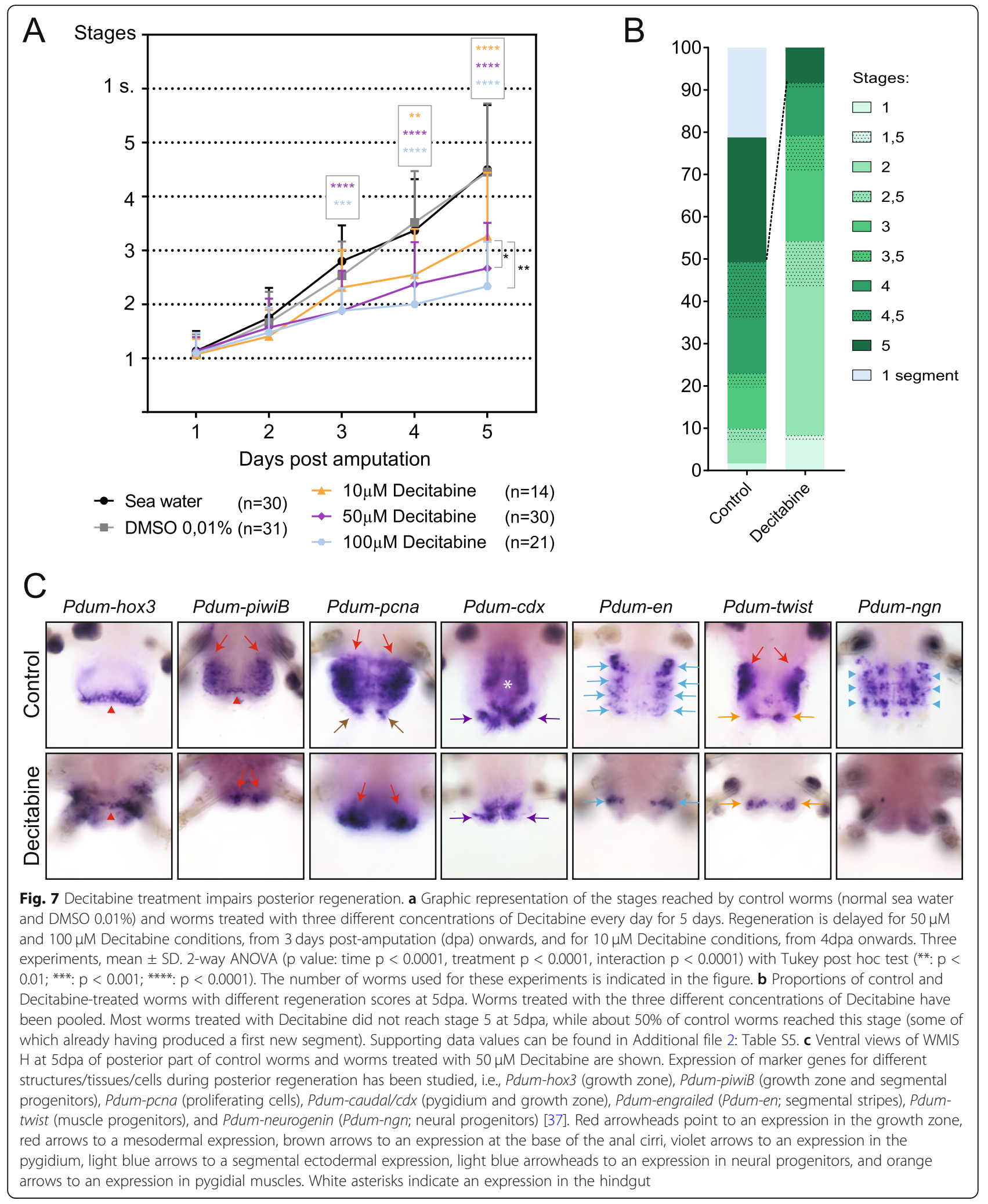

Class 2 animals (61.6\%) have an abnormal body shape, a reduced number of newly added segments, an absence of well-differentiated parapodia on newly added segments, and no or abnormal anal cirri. Class 3 worms (7.9\%) have a morphology and number of newly added segments similar to control animals. 

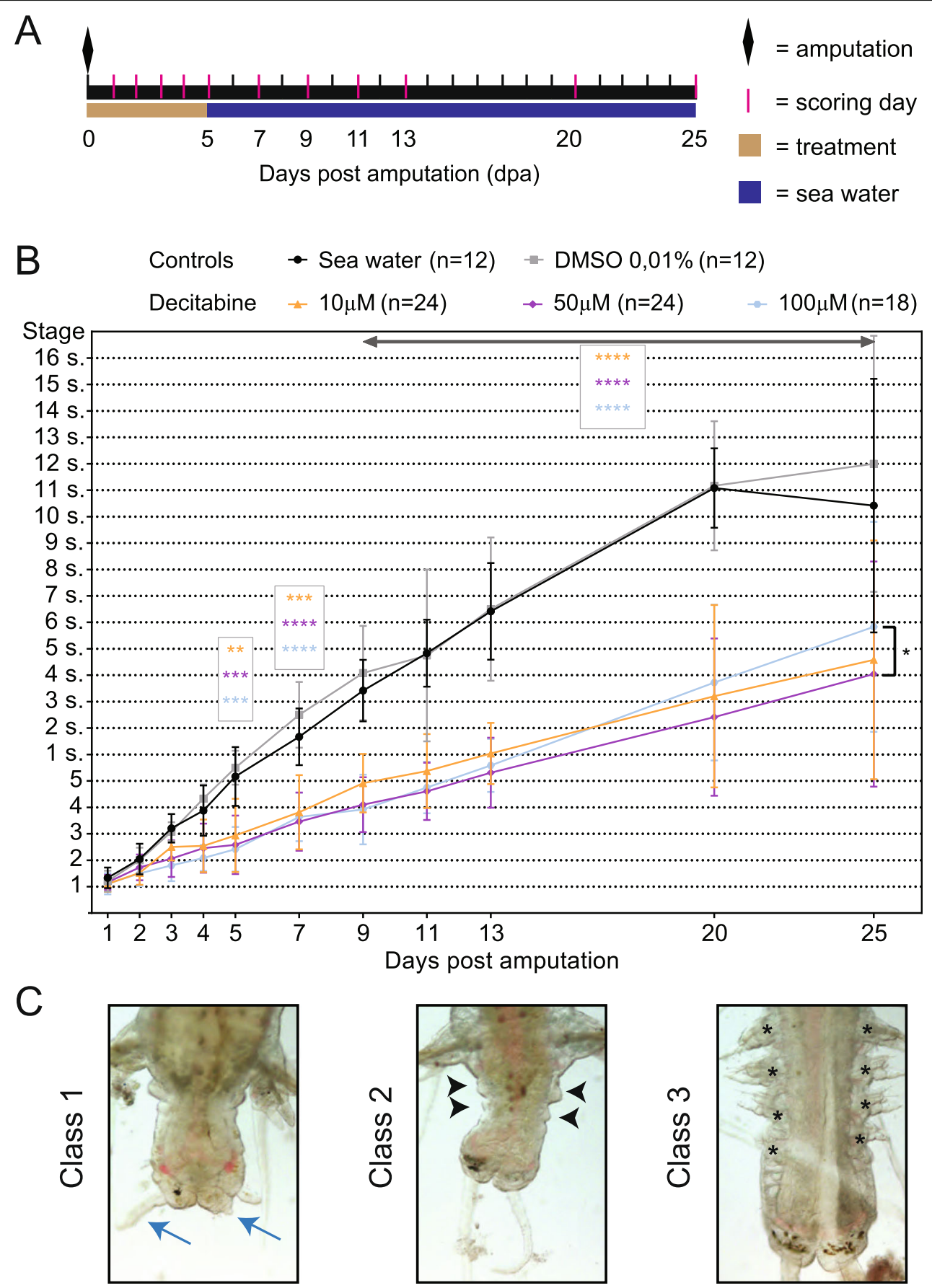

Fig. 8 Decitabine treatment during posterior regeneration affects subsequent post-regenerative posterior growth. a Schematic representation of the experimental design. Worms were treated with Decitabine $(10 \mu \mathrm{M}, 50 \mu \mathrm{M}$, or $100 \mu \mathrm{M})$ or from amputation to $5 \mathrm{dpa}$. Control animals were treated with DMSO $0.01 \%$ or put in normal seawater. After washing out, worms were kept from $5 \mathrm{dpa}$ to $25 \mathrm{dpa}$ in normal seawater and observed at several time points until $25 \mathrm{dpa}$. $\mathbf{b}$ Graphic representation of regeneration stages that have been reached or numbers of newly added segments by Decitabine-treated and control worms. A significant delay in post-regenerative posterior growth is observed in Decitabine-treated worms as compared to controls. Two experiments, mean \pm SD, 2-way ANOVA ( $p$ value: time $p<0.0001$, treatment $p<0.0001$, interaction $p<0.0001$ ) with Tukey post hoc test $\left(* *: p<0.01 ;{ }^{* *}: p<0.001 ; *^{* * *}: p<0.0001\right)$. Only $p$ values corresponding to comparison to normal seawater are shown, as highly similar ones are obtained for comparison to DMSO controls. The number of worms used for these experiments is indicated in the figure. Supporting data values can be found in Additional file 2: Table S6. c Representative morphologies at $25 \mathrm{dpa}$ of worms belonging to the three defined classes (see main text for details). While class 3 worms showed well-differentiated segments with parapodia (black asterisks), no or reduced parapodia were observed in class 1 and class 2 (black arrowheads) worms, respectively. Small or abnormally shaped anal cirri (blue arrows) were also frequently observed in class 1 and 2 worms 
Taken together, these observations indicate that Decitabine treatments during regeneration have long-term effects and affect subsequent post-regenerative posterior growth, possibly by affecting growth zone regeneration. Some Decitabine-treated worms were however able to add new segments in an almost normal manner, which led us to hypothesize that the growth zone was not impacted similarly in all animals. To point out a potential link between regeneration of the growth zone and ability to later add segments, we performed a multiple correlation analysis (Additional file 15: Fig. S13). In control worms, as expected, only positive correlations were observed, which means that, for example, worms with numerous segments at 20dpa already had a high number of segments at 11dpa. In contrast, in Decitabine-treated worms, while there were positive correlations for closely related days of scoring (for example: 2 to $3 \mathrm{dpa}, 3$ to $4 \mathrm{dpa}, . .$.$) , negative correlations were also found and sug-$ gested that treated worms that regenerated faster eventually produced less segments. It has been shown that the growth zone is regenerated and becomes functional, producing news segments, at about 3dpa [37]. Our interpretation is therefore that worms with high regeneration scores (scored at stage 3 or more) at $5 \mathrm{dpa}$ regenerated a dysfunctional growth zone in the presence of Decitabine, which later led to a null or reduced production of segments, the few segments produced additionally displaying morphological abnormalities. Worms with low scores (less than 3) probably did not regenerate their growth zone during the Decitabine treatment period and did it after $5 \mathrm{dpa}$ in the absence of the drug, which led to the formation of a functional growth zone and therefore to normal segment addition. Our data therefore suggest that Decitabine affects the functionality of the growth zone. Consistently, expression of growth zone, stem cell, and segment markers (Pdum-hox3, Pdum-piwiB and Pdum-engrailed, respectively) is affected in some Decitabine-treated worms (Fig. 7c).

As described above, worms treated with Decitabine from 0 to $5 \mathrm{dpa}$ show morphological abnormalities at $25 \mathrm{dpa}$. To better understand these alterations, we performed WMISH on Decitabine-treated worms at $25 \mathrm{dpa}$ for a set of previously studied marker genes [37]. A wide range of abnormal expression patterns were found in Decitabine-treated worms (Fig. 9). This includes a reduced number of segmental stripes of Pdum-engrailed in worms with few morphologically visible segments (Fig. 9a1-a3), reduced expression of Pdum-dlx (which is normally expressed at the base of anal cirri and in parapodia), on one side of the worm (Fig. 9b1-b3), as well as ectopic expression of Pdumhox3, Pdum-cdx, and Pdum-piwiB in developing segments (Fig. 9c1-e3), which are consistent with persistent defects in growth zone functionality.
Finally, we investigated whether Decitabine might have effects over an even longer time period. We treated worms with Decitabine from 0 to $5 \mathrm{dpa}$, then put them in normal sea water until $25 \mathrm{dpa}$, performed a second amputation one segment anterior to the first amputation plan (meaning that we eliminated the regenerated region plus one segment), and scored these worms at several time points until 18 days postsecond amputation (18dpSa; Additional file 16: Fig. S14A). Control and Decitabine-treated worms regenerated properly and similarly after this second amputation and were able to add new segments at a similar rate (Additional file 16: Fig. S14B). A slight but significant delay, however, was observed for worms treated with $10 \mu \mathrm{M}$ Decitabine at $18 \mathrm{dpSa}$ (Additional file 16: Fig. S14B) and about $10-15 \%$ of Decitabine-treated worms showed minor defects at the level of their parapodia (Additional file 16: Fig. $\mathrm{S} 14 \mathrm{C})$. A same proportion of worms that were class 1 or 2 at 25dpa showed abnormalities after the second amputation at 18dpSa (Additional file 16: Fig. S14C). Multiple correlation analysis showed that, for both control and Decitabine-treated worms, only positive correlations were found (Additional file 16: Fig. S14D, E). Therefore, Decitabine treatments after a first amputation have only very minor effects on regeneration and post-regenerative posterior growth occurring after a second amputation.

On the whole, our data show that Decitabine decreases methylation levels in $P$. dumerilii and affects larval development and regeneration. During regeneration, it impairs post-regenerative posterior growth occurring in the absence of the drug, a long-term effect that could be due to defects in the regeneration of the stem cell-containing growth zone.

\section{Discussion}

A wealth of studies, mainly conducted in mammals, pointed out that cytosine DNA methylation modulates gene expression and is of primary importance for the regulation of embryonic development and stem cell properties [7]. Mechanisms and biological roles of this epigenetic modification in non-vertebrate species, and in other processes such as regeneration, has however been much less studied. This is at least in part due to the fact that canonical non-vertebrate developmental models such as Drosophila melanogaster and Caenorhabditis elegans [9], and canonical regeneration models such as planarians [65], almost entirely lack $5 \mathrm{mC}$ and are therefore of no help for understanding its functions in nonvertebrates. In this article, we study cytosine DNA methylation and its roles during development, regeneration, and post-regenerative growth in an emerging 

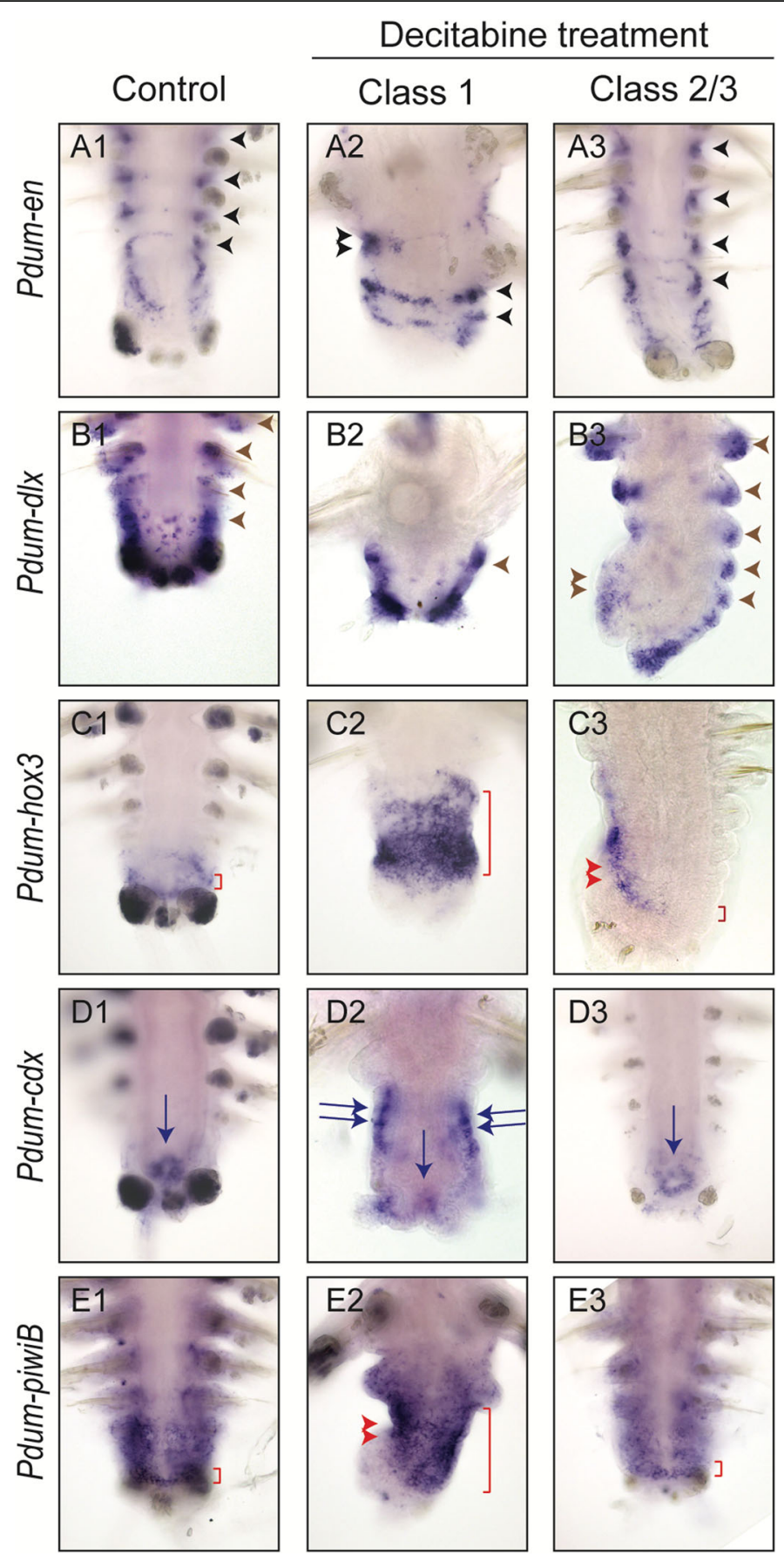

Fig. 9 Gene expression at 25 days post-amputation in worms that have been treated with Decitabine during regeneration. WMISH at 25 dpa of posterior parts of control worms and worms treated with $50 \mu \mathrm{M}$ Decitabine from 0 to $5 \mathrm{dpa}$ for selected markers, i.e., Pdum-engrailed (Pdum-en; segmental stripes), Pdum-dlx (parapodia and anal cirri), Pdum-hox3 (growth zone), Pdum-caudal/cdx (pygidium and growth zone), and Pdum-piwiB (growth zone and segmental progenitors). Two Decitabine-treated worms with more or less altered morphologies (class 1 and class 2/3) are shown for each gene. In A1-A3, black arrowheads point to segmental stripes of Pdum-en expression. In $A 2$, the double black arrowhead points to an incomplete expression stripe. In B1-B3, brown arrowheads point to the expression of Pdum-dlx in developing parapodia. In B3, a reduced Pdum-dlx expression is observed on one side of the worm (double brown arrowhead). In C1, red bracket delineates the expression of Pdum-hox3 in the ectodermal growth zone. A very large domain of Pdum-hox3 is found in class 1 worms (red bracket in C2). An abnormal expression pattern is also observed in class 2/3 worms (red bracket and double red arrowhead in C3). In D1-D3, blue arrows point to the expression of Pdum-cdx in the posterior gut region and double blue arrows point to an ectopic expression of the gene in developing segments (D2). In E1-E3, red bracket delineates a strong expression of Pdum-piwiB in the mesodermal growth zone. Pdum-piwiB is also expressed in the developing mesoderm in a graded manner. In E2, a strong and broad expression is found throughout the regenerated region (red bracket and double red arrowhead) 
developmental and evolutionary biology model species, the marine annelid Platynereis dumerilii.

\section{P. dumerilii genome displays a high and dynamic level of CpG methylation}

One of the main aims of our study was to define the extent and pattern of DNA methylation in the annelid $P$. dumerilii. Three main types of methylation patterns are classically described in animals: (i) global high-level methylation often presented as characteristic of vertebrates, in which a large majority of CpGs are methylated; (ii) mosaic low-/intermediate-level methylation in which only some genomic regions are methylated (interspaced with non-methylated ones) found in many diverse nonvertebrates; (iii) ultra-low/no methylation found in some species such as Drosophila melanogaster, Caenorhabditis elegans, and Schmidtea mediterranea [11, 48, 50, 66]. Here, we combined in silico (computation of CpG o/e ratios [43, 48]) (Fig. 1a) and experimental (genomic DNA digestion with methylation-sensitive enzymes and LUminometric Methylation Assay (LUMA [53, 54])) (Fig. 1b, c) approaches to identify high levels of CpG methylation in $P$. dumerilii (up to more than $80 \%$ at some developmental stages) comparable to those of mammalian somatic cells [5, 67]. While this high-level vertebrate-like methylation may seem surprising in a non-vertebrate species, it has also been demonstrated by whole-genome bisulfite sequencing in the sponge Amphimedon queenslandica (and is supported by the low CpG o/e ratios of this species) [33] and the crustacean Parhyale hawaiensis [32], showing that high-level methylation can also occur in non-vertebrate species. While our data indicate gene body methylation, as CpG o/e ratio calculation (Fig. 1a) and bisulfite pyrosequencing (Fig. 1d) were done on coding regions, further analyses, in particular whole-genome bisulfite sequencing, will be required to better characterize $P$. dumerilii genome methylation. Further characterization would include, for example, the determination of whether there is $5 \mathrm{mC}$ depletion at gene promoters (like in A. queenslandica and vertebrates [33]) and to point out putative $5 \mathrm{mC}$ methylation in repetitive DNA (such as transposable elements), which is widely found in eukaryotes [7, 9]. In addition, the question of whether high-level genome methylation could be more widespread in animals than expected deserves to be experimentally addressed, as the patterns and extent of DNA methylation are known in rather few animal species so far and CpG o/e ratio calculations suggested that high-level methylation might exist in other non-vertebrate animals [48] (Fig. 2; Additional file 3: Fig. S2).

An intriguing observation made about $P$. dumerilii DNA methylation is the sharp decrease of the $5 \mathrm{mC}$ level, observed by LUMA, from more than $80 \%$ of methylated
CCGG sites at embryonic/larval stage (12 to $72 \mathrm{~h}$ postfertilization, hpf) to about $60-65 \%$ at post-larval stages (4, 5, and 15 days post-fertilization, dpf) (Fig. 1c). It is important to note that for technical reasons we were unable to obtain LUMA data from very early developmental stages, the earliest studied one being $12 \mathrm{hpf}$ which roughly corresponds to a late gastrula stage [35]. Later time points (24, 48 , and $72 \mathrm{hpf}$ ) correspond to organogenesis stages during which many cells and tissues are differentiating. We cannot extrapolate methylation levels of earlier $0-12 \mathrm{hpf}$ stages, neither can we exclude that demethylation after fertilization may occur followed by remethylation during cleavage/early gastrulation stage, similarly to what has been observed in mammals [7]. In mammals, the methylation level remains high in somatic cells from the epiblast stage onwards and a transient decrease of this level only occurs in the germ cell lineage [7]. In contrast, in $P$. dumerilii a sharp decrease in the DNA methylation level happens in the $72 \mathrm{hpf}$ to 4,5 , and $15 \mathrm{dpf}$ time period, which corresponds to a major transition in the life cycle of the animal, the metamorphosis of the larva into a benthic feeding juvenile worm that adds new segments by posterior growth $[35,36]$. The methylation level further decreases in older juvenile worms (3mpf) and subsequently re-increases at the time of sexual maturation (a process known as epitoky), another key transition in the life cycle of $P$. dumerilii, as it involves dramatic changes in the morphology, anatomy, and behavior of the worm [35]. Such changes of DNA methylation levels at critical developmental transitions have also been reported in other non-vertebrates, for example at the time of metamorphosis in the oyster Crassostrea gigas [31] and in Xenopus [68], or during caste attribution in social hymenopterans (e.g., [41, 69]). Changes in the DNA methylation level could therefore be important for key developmental transitions in distantly related animals, a tempting hypothesis that nevertheless remains to be experimentally tested.

\section{P. dumerilii possesses an ancestral-like repertoire of DNA methylation and NuRD toolkit genes that show dynamic expression during development and regeneration}

We retrieved and analyzed a large dataset of genes encoding putative writers, modifiers, and readers of $5 \mathrm{mC}$, as well as NuRD members and related proteins. This dataset corresponds to 17 gene families/subfamilies for which we reported the presence/absence and number of members in each of the 54 studied species (Fig. 2). Using these data, we were able to infer parsimoniously the likely presence or absence of each gene family in the last common ancestors of metazoans and bilaterians (Fig. 3). Our conclusions are in agreement with, and reinforce, those of previous studies made on a more limited set of gene families and/or studied species (e.g., [22, 27, 30, 33, $56,70])$. A complex DNA methylation and NuRD toolkit 
was present in the last common ancestor of all animals that probably possessed at least one member of the 17 analyzed families/subfamilies (Fig. 3). This toolkit has been remarkably conserved during animal evolution as shown by the small number of missing orthologs in most species (Fig. 2), a number likely to be overestimated as most species only benefit from draft genome assemblies. Exceptions are species in which gene losses occurred frequently such as nematodes, some insects, and flatworms. In these species, very low/no genome methylation was reported and several genes of the methylation toolkit (mainly Dnmt and Uhrf genes) are absent. Similar reduced toolkits are found in the placozoan Trichoplax adhaerens and the tardigrade Hypsibius dujardini, suggesting that these two species may also have no or very reduced genome methylation (as also hinted by $\mathrm{CpG}$ o/e values). Besides these extreme cases, there is no clear connection between the number of genes encoding $5 \mathrm{mC}$ machinery proteins and the pattern of genome methylation inferred from CpG o/e calculation (Fig. 2) or experimental analysis [64].

We identified members of all 17 gene families/subfamilies in P. dumerilii with single-copy members for 16 of them (Fig. 2; the only exception is the CHD3/4/5 subfamily for which four members were found), consistent with the hypothesis that $P$. dumerilii belongs to a slowevolving lineage in which few gene loss and duplication events occurred [71, 72]. To have a first glimpse of the possible function of these genes in $P$. dumerilii, we looked at their expression at the mRNA level, using transcriptomic data (for developmental and adult stages) and whole-mount in situ hybridization data (for regeneration stages). Most DNA methylation and NuRD genes are expressed at most or all stages of the $P$. dumerilii life cycle (Fig. 4), which is expected for genes encoding epigenetic regulators likely involved in multiple steps of the life cycle of the animal. However, many genes show dynamic expression during embryonic/larval development, at juvenile and adult stages, as well as during regeneration. Interestingly, at the transition between larval/postlarval stages, expression of Pdum-dnmt1 and Pdum-uhrf, which could be involved in DNA methylation maintenance like their vertebrate orthologs [16], decreases, while expression of Pdum-tet, likely involved in demethylation $[18,19]$, increases (Fig. 4). This suggests that the marked decrease in the DNA methylation level observed at this transition (see above) could be due to either passive (Dnmt1-mediated) or active (Tet-mediated) demethylation, or to both mechanisms.

We also characterized the expression of several DNA methylation and NuRD genes during regeneration and found these genes to be expressed at all stages of the process (Fig. 5). Strikingly, all the studied genes are expressed at stage 1 in cells of the wound epithelium and/or cells of the immediately adjacent segment, which would fit with an early role of these genes during regeneration. From stage 2 onwards, all genes are expressed in the regeneration blastema and subsequently in the regenerating segments, in patterns that are reminiscent of those previously reported for stem cell and proliferation genes [37], suggesting an expression in proliferating cells and therefore that DNA methylation could be important for the formation of the regenerated structures from blastemal cells. These expression data are also consistent with the hypothesis that DNA methylation might be involved during multiple steps of regeneration in P. dumerilii.

\section{Decitabine treatments suggest that DNA methylation is involved in $P$. dumerilii development, regeneration, and post-regenerative growth}

To study the putative functions of DNA $5 \mathrm{mC}$ methylation during $P$. dumerilii development and regeneration, we treated larvae or regenerating worms with Decitabine (5-aza-2'-deoxycytidine), a hypomethylating agent that causes cell-division-dependent DNA demethylation by blocking Dnmt1 activity [61-63]. While widely used in vertebrates, especially humans, this chemical has only been sparsely used in non-vertebrates [73-75] and, to our knowledge, never used during regeneration or in annelids. We therefore first obtained evidence that Decitabine does indeed lead to DNA demethylation in $P$. dumerilii by showing a 2.5 -fold decrease of CCGG methylation in $72 \mathrm{hpf}$ larvae treated with Decitabine for 2 days, as compared to control animals (Fig. 6b). Decitabine is thus an appropriate tool to study possible roles of DNA methylation in P. dumerilii.

We observed three main effects for Decitabine. First, when applied during larval development (from $1 \mathrm{dpf}$ to 3dpf), Decitabine produced significant morphological defects but did not block development or led to larval death (Fig. 6c). Some developmental processes, such as appendage (parapodia) and pygidium formation, are strongly affected (as shown by the extreme reduction of these structures in Decitabine-treated larvae), while others, such as segmentation, are less or not affected. This could indicate differential requirements of DNA methylation for specific developmental process. Alternatively, it could be due to the mode of action of Decitabine that induces a progressive loss of $5 \mathrm{mC}$ through cell divisions, meaning that a significant decrease in $5 \mathrm{mC}$ level is probably achieved only several hours after the start of Decitabine treatment. In this view, Decitabine treatment may not affect developmental processes that happen before or soon after 24hpf, for example segmentation (segmental stripes of Pdum-engrailed expression can already be seen at $18 \mathrm{hpf}$ [76]), while strongly affecting processes starting later in development, for example 
pygidium formation that is still ongoing at the end of the treatment at $3 \mathrm{dpf}$ [77]. In the future, it would be interesting to further assess the effects of Decitabine on $P$. dumerilii development, in particular through the use of other temporal windows of treatment, including windows spanning early development (0-24hpf) which could produce much more severe defects, as observed in the oyster C. gigas in which gastrulation was severely impacted when Decitabine was applied on early development stages [73]. Effects of Decitabine on germ cell specification and development, which are well characterized in P. dumerilii [78], would also be an interesting topic for future examination, given the importance of DNA (de)methylation in the germ cell lineage [7].

A second clear effect of Decitabine is that it strongly delays regeneration when applied on worms for 5 days, from 0 to $5 \mathrm{dpa}$ (Fig. 7a, b). Indeed, at day 5 after amputation, Decitabine-treated worms mostly reached stage 2 or 3 , while controls worms reached stage 4 or 5 . This is similar to what has been observed when applying the proliferation inhibitor hydroxyurea on regenerating worms [37]. On the one hand, this is consistent with the antiproliferative effect of Decitabine observed in humans, for whom this drug has been used for a long time, at a high concentration, as an anticancer cytotoxic drug preventing DNA replication, thereby blocking cell proliferation and leading to cell death [79, 80]. On the other hand, several elements suggest that the effect of Decitabine on regeneration in $P$. dumerilii could be due to demethylation and not to an impairment of DNA replication. The first and most compelling argument is that we used low Decitabine concentrations that effectively led to significant demethylation (Fig. 6b). As this Decitabine-induced demethylation can only occur after several cell divisions, it could not be obtained if Decitabine was used at concentrations that block cell divisions and has a cytotoxic effect $[79,80]$. In humans, Decitabine is now used at low dosage to maximize its hypomethylating action, which elicits better anticancer responses than when used at higher concentrations [79]. Secondly, while there are many cell divisions which happens during larval development ( 1 to $3 \mathrm{dpf}$ time period; e.g., [81]), Decitabine treatment leads to $3 \mathrm{dpf}$ larvae with a size and a body shape similar to control ones strongly arguing against an antiproliferative effect of Decitabine at the used concentrations. Thirdly, after washing out the drug, Decitabine-treated worms were able to rapidly resume regeneration in a normal manner, which does not support the claim of Decitabine having significant cytotoxic effects. Our current hypothesis is therefore that Decitabine delays regeneration through its hypomethylating effect and therefore that DNA methylation may be required for proper regeneration in $P$. dumerilii. This hypothesis is at odds with what has been described in vertebrates in which demethylation has been suggested to be a driver of regeneration, in the axolotl limb [40], zebrafish fin [39], and the chick retina [82]. Additional experiments will be required to further test the requirement of DNA methylation in $P$. dumerilii regeneration and identify the involved mechanisms. An obvious possibility would be that massive demethylation induced by Decitabine may interfere with the expression of genes involved in regeneration, as suggested by reduced expression of Pdum-hox3, Pdum-piwiB, and Pdum-engrailed in Decitabine-treated worms (Fig. 7c), thereby hampering successful regeneration.

A third compelling effect of Decitabine is that, when applied during 5 days after amputation, it interfered with post-regenerative posterior growth that occurs once regeneration has resumed and been completed in absence of the drug (Fig. 8a, b). These worms showed a reduced rate of segment addition compared to control animals and displayed segments with various abnormalities and severely affected gene expression patterns at $25 \mathrm{dpa}$, i.e., 20 days after drug removal (Figs. 8 and 9). Based on multiple correlation analysis (Additional file 15: Fig. S13) and altered gene expression patterns of stem cell, growth zone, and segmental marker genes in Decitabine-treated worms at $5 \mathrm{dpa}$ (Fig. 7c), we suggest that drug-mediated DNA hypomethylation affects gene expression in stem cells of the growth zone, thereby impairing its functionality and subsequent posterior growth. Abnormal expression of growth zone markers is still observed in some worms at $25 \mathrm{dpa}$ (Fig. 9), consistent with the hypothesis of an epigenetic modification (hypomethylation) that has been transmitted during the many cell divisions that occur during the $5 \mathrm{dpa}$ to $25 \mathrm{dpa}$ time period. Along the same line, parapodia formation, which starts after the drug has been removed, is also strongly affected in many Decitabine-treated worms, suggesting that DNA hypomethylation might have been transmitted from growth zone stem cells to parapodial progenitors, leading to altered gene expression during parapodia formation, as shown for Pdum-dlx (Fig. 9), and defects in this process.

Our data therefore suggest that $5 \mathrm{mC}$ DNA methylation is important for the function of stem cells of the growth zone in $P$. dumerilii, i.e., somatic adult stem cells, and their capability to produce differentiated structures such as segments and appendages. Growth zone stem cells express a set of genes, such as piwi, vasa, and nanos, that constitutes the Germline Multipotency Program (GMP) shared with primordial germ cells and pluripotent/multipotent somatic stem cells in other animals [36, 83]. In mammals, in the absence of DNA methylation, ES cells keep their stem cell identity and their self-renewal ability, but their differentiation is almost completely abolished, due to a failure to upregulate 
germ-layer-specific genes and to silence pluripotency genes (e.g., [84]). Roles of DNA methylation have also been described in mammalian adult stem cells for both stem cell self-renewal and differentiation capabilities (e.g., [85-87]). A tempting hypothesis is therefore that Decitabine-induced hypomethylation in $P$. dumerilii growth zone stems cells may alter their ability to produce differentiated cell lineages required for segment and appendage formation. Supporting this is our observation of ectopic expression of growth zone markers, Pdum-hox3, Pdum-cdx, and Pdum-piwiB, in developing segments of $25 \mathrm{dpf}$ worms that had been treated from 0 to $5 \mathrm{dpf}$ with Decitabine (Fig. 9), suggesting that the silencing of stem cell markers in segmental progenitors/ differentiated cells might not be properly done in a hypomethylated context. Further tests of this hypothesis would require a specific assessment of methylation levels in growth zone stem cells and their progeny, which is currently not possible due to the lack of tools to isolate and culture these cells.

\section{Conclusion}

We provide data that strongly suggest that the genome of $P$. dumerilii is highly methylated and that the methylation level changes during development. We show that $P$. dumerilii harbors a mostly single-copy repertoire of DNA methylation and NuRD genes that have dynamic expression patterns during development and regeneration. Using the hypomethylating drug Decitabine, we obtained functional data in favor of an involvement of $5 \mathrm{mC}$ DNA methylation during development, regeneration, and post-regenerative growth. These data also suggest that Decitabine-induced hypomethylation of growth zone stem cells could alter their capability to produce differentiated segments. However, the mechanisms by which DNA methylation acts in P. dumerilii remain elusive and further studies will be required to define whether it controls transcription and/or other aspects of gene expression regulation. The possible presence and roles of $5 \mathrm{mC}$ in repetitive DNA such as transposable elements should also be characterized. When considered as a whole, our data provide the first evidence of the roles of the $5 \mathrm{mC}$ epigenetic mark during regeneration outside of vertebrates. Our study also lays the groundwork for using $P$. dumerilii as a new nonvertebrate model to study $5 \mathrm{mC}$ DNA methylation, and other epigenetic regulations, in particular those involving histone modifications, during development, regeneration, and stem cell-based growth.

\section{Methods}

\section{$P$. dumerilii gene identification and cloning}

Putative $P$. dumerilii orthologs of genes known to encode protein involved in $5 \mathrm{mC}$ methylation or to belong to $\mathrm{NuRD}$ complex (and related proteins) were identified by BLAST searches [88] on available transcriptomic and genomic data, using $H$. sapiens and $M$. musculus protein sequences as queries. Sequences of all identified genes can be found in Additional file 5. Conserved domains in $P$. dumerilii and $H$. sapiens proteins (Additional file 4: Fig. S3) were identified using InterPro 80.0 [89] and the NCBI CD-Search Tools [90]. High-fidelity PCR with gene-specific primers (listed in Additional file 2: Table S7) was used to amplify gene fragments using as a template cDNA from mixed larval and regenerating stages with, for some genes, a touchdown approach. PCR products were purified (740609, Macherey Nagel), and TA cloned in the pCR2.1 vector (K450001, Thermo Fisher), following the manufacturer's instructions. Sequences of cloned genes were verified by Sanger sequencing (Eurofins Genomics). GenBank accession numbers for $P$. dumerilii genes: MW250929 to MW250948.

\section{Phylogenetic analyses and establishment of orthology relationships}

Putative members of all studied $5 \mathrm{mC}$ machinery gene families were identified by sequence similarity searches (reciprocal best BLAST hit approach [88]) on publicly available genome sequences of 51 different species belonging to all major animal clades (Fig. 2) using H. sapiens and M. musculus sequences as queries. Redundant sequences were manually discarded and, in some cases, incomplete short sequences were concatenated. To obtain outgroups for subsequent phylogenetic analyses, members of all families were also searched for in two choanoflagellate species, Monosiga brevicollis (Mbre) and Salpingoeca rosetta (Sros), as well as, in the case of unsuccessful searches, in available transcriptomes of other choanoflagellate species. For some gene families (DNMT, CHD, and HDAC), sequences from distinct but related families (DNMT5, SNF2L1, and class II/IV HDACs) were retrieved to be used as outgroups for phylogenetic tree rooting. All identified sequences can be found in Additional file 5. Databases used to retrieve these sequences are listed in Additional file 2: Table S8.

Multiple alignments were obtained using MUSCLE 3.8.31 [91] (available on the MPI Bioinformatics Toolkit platform [92]) and subsequently improved either manually or using the BMGE 1.1.2 software [93]. Multiple alignments were visualized using SEAVIEW 5.0.4 [94]. Maximum likelihood (ML) analyses were performed using the PHYML 3.0 software $[95,96]$. The amino acid substitution model was defined by the software using SMS with the Akaike Information Criterion [97]. Other parameters (such as proportion of invariable sites and Gamma shape parameter) were estimated from the datasets by the software. The tree improvement method was NNI and statistical supports for internal branches of 
trees were assessed by approximate likelihood-ratio test (aLRT) [98, 99]. Phylogenetic trees were handled using FigTree 1.4.

\section{CpG o/e ratio calculations}

Notos [43] was used to calculate and model CpG o/e (observed/expected) as described in Aliaga et al. [48] for the $P$. dumerilii reference transcriptome and transcriptomes of some of the 54 studied species for which CpG $\mathrm{o} / \mathrm{e}$ ratios were not previously determined [48]. The formula $(\mathrm{CpG} /(\mathrm{C} \times \mathrm{G})) \times\left(\mathrm{L}^{\wedge} 2 / \mathrm{L}-1\right)$ and a minimum length of $200 \mathrm{bp}$ were used.

\section{$P$. dumerilii breeding culture and posterior amputation procedure}

$P$. dumerilii embryos, larvae, and juvenile worms were obtained from a breeding culture established at the Institut Jacques Monod (Paris, France). For regeneration experiments, amputations of posterior parts were performed on juvenile worms of 3-4 months and 30 to 40 segments as previously described [37].

\section{Study of DNA methylation levels in $P$. dumerilii}

Methylation of genomic DNA (gDNA) of P. dumerilii, $N$. vectensis (adult), D. melanogaster (adult), B. floridae (adult), H. sapiens (HCT116 cells), and M. musculus (embryonic stem cells, mESC) was assessed by digesting 500 to $800 \mathrm{ng}$ of gDNA with $1 \mu \mathrm{L}$ of restriction enzymes HpaII or MspI in $50 \mu \mathrm{L}$ containing $1 \mathrm{X}$ FastDigest green buffer (FD0514 and FD0544, Thermo Scientific) for 15 min at $37^{\circ} \mathrm{C}$. Then, $300 \mathrm{ng}$ of undigested gDNA and from each restriction reaction were loaded in a $1 \%$ agarose gel with molecular weight marker (N3232, NEB). A $160 \mathrm{~V}$ current was applied for $30 \mathrm{~min}$ in a Midigel tank (370000, Apelex), and ethidium bromide was used with a UV-transilluminator for revelation. This experiment was repeated twice using genomic DNA from independent DNA extractions.

To evaluate global DNA methylation levels, we used a LUminometric Methylation Assay (LUMA) based on enzymatic digestion and pyrosequencing $[53,54]$. For each studied stage, at least two biological replicates (larvae and worms from different fertilizations) were analyzed with at least two technical replicates for each biological replicate. Samples were washed twice with $200 \mathrm{mM}$ PBS $0.1 \%$ Tween on ice before freezing at $-80^{\circ} \mathrm{C}$. DNA was extracted using the DNA/RNA All prep kit (80204, Qiagen) following the manufacturer's instructions. DNA was stored at $-20^{\circ} \mathrm{C}$ prior to LUMA analysis. Prior to LUMA analysis, DNA integrity and sample purity were assessed using Tapestation (Agilent). Only samples with a DNA Integrity Number superior or equal to 8 were kept for subsequence analysis. LUMA experiments were performed as in Karimi et al. [53] with internal controls
(HCT116 WT and DKO (Dnmt1-/-; Dnmt3b-/-)). Then, $250 \mathrm{ng}$ of gDNA was digested with HpaII+EcoRI or MspI+EcoRI for $4 \mathrm{~h}$ at $37^{\circ} \mathrm{C}$. Then, samples were analyzed in a PyroMark Q24 (Qiagen). The instrument was programmed to add dNTPs as follows: dATP; dGTP + dCTP; dTTP; H2O as control; dGTP + dCTP; dATP; dTTP. Peak heights were calculated using the PyroMark Q24 software (Qiagen). The HpaII/EcoRI and MspI/ EcoRI ratios were calculated as $(\mathrm{dGTP}+\mathrm{dCTP}) /$ mean (dATP; dTTP) for the respective reactions. The percentage of methylated CCGG sites was defined as: $100 \times[1$ - (HpaII/EcoRI)/(MspI/EcoRI)].

To measure CpG methylation levels in the 14-3-3-like and Histone $\mathrm{H} 4$ genes, we used bisulfite pyrosequencing. Pyrosequencing primers (listed in Additional file 2: Table S7) were designed using the PyroMark Assay Design Software 2.0 (Qiagen). Then, $500 \mathrm{ng}$ of genomic DNA was subjected to bisulfite conversion using the EpiTect Bisulfite Kit (Qiagen, Catalog No. 59124). PCR reactions were performed in a final volume of $25 \mu \mathrm{L}$, using the Pyromark PCR kit (Qiagen, Catalog No. 978703), with one of the primers biotinylated and containing $12.5 \mathrm{ng}$ of bisulfite-treated DNA. The initial denaturation/activation step was performed at $95^{\circ} \mathrm{C}, 15$ min, followed by 50 cycles of $30 \mathrm{~s}$ at $94{ }^{\circ} \mathrm{C}, 30 \mathrm{~s}$ at $54{ }^{\circ} \mathrm{C}$, $45 \mathrm{~s}$ at $72^{\circ} \mathrm{C}$, and a final extension step at $72{ }^{\circ} \mathrm{C}$ for 10 min. The quality and the size of the PCR products were evaluated by running $5 \mu \mathrm{L}$ of each PCR product on $1.5 \%$ $(\mathrm{w} / \mathrm{v})$ agarose gel in a $0.5 \mathrm{X}$ TBE buffer. Biotinylated PCR products $(20 \mu \mathrm{L})$ were immobilized on streptavidincoated sepharose beads (GE Healthcare, 17-5113-01). DNA strands were separated using the PyroMark Q24 Vacuum Workstation, and biotinylated single strands were annealed with $0.375 \mu \mathrm{M}$ sequencing primer and used as a template for pyrosequencing. Pyrosequencing was performed using PyroMark Q24 Advanced (Qiagen, Catalog No. 9002270) according to the manufacturer's instructions, and data about methylation at each CpG was extracted and analyzed using the PyroMark Q24 Advanced 3.0.0 software (Qiagen). For each studied stage, two biological replicates (larvae and worms from different fertilizations) were analyzed with two technical replicates for each biological replicate.

\section{Whole-mount in situ hybridizations (WMISH) and imaging} For probe synthesis, plasmid containing appropriate cDNA were purified (740588 and 740412, Macherey Nagel), digested (NEB enzyme), and used to produce digoxygenin-labeled RNA antisense probes (Synthesis with Roche reagents: 11093274910 and 10881767001 or 10810274001; Purification with 740955, Macherey Nagel) as previously described [36]. WMISH were done as previously described [37, 100]. As in previous studies that used this WMISH protocol [37, 100], WMISH with 
sense probes only gave non-specific labeling in the mucus-secreting glands which are found in the pygidium and parapodia. For each stage and each gene, at least five individuals were analyzed. Bright-field images were taken on a Leica microscope. Adjustment of brightness and contrast were performed using Photoshop software.

\section{Decitabine and RG108 treatments}

Stock solution of $200 \mathrm{mM}$ Decitabine (5' -Aza-2'-deoxycytidine) and $10 \mathrm{mM}$ RG108 (N-Phthalyl-L-Tryptophan) in DMSO were diluted in seawater to obtain different concentrations as described in the "Results" section. DMSO controls correspond to a concentration of DMSO in seawater corresponding to that of $100 \mu \mathrm{M}$ Decitabine condition. In order to assess methylation levels with LUMA after Decitabine or RG108 treatment, larvae were kept 2 days (1 to 3dpf) in $30 \mathrm{ml}$ of Decitabine- or RG108containing seawater before washing and freezing. Two or three biological replicates (larvae from different fertilizations) were analyzed with two technical replicates for each biological replicate. For morphological studies, larvae were washed out, kept in normal seawater, and fed from $5 \mathrm{dpf}$ onwards. Larvae were anesthetized with $7.5 \% \mathrm{MgCl}_{2}$ before observations. The experiment was repeated twice using larvae from different fertilizations.

Amputated worms were placed individually in 12-well plates in $2 \mathrm{ml}$ of Decitabine solution or control solution that was changed every day for 5 days. For posterior growth analyses, worms were subsequently placed in normal sea water until $25 \mathrm{dpa}$. For some experiments, at $25 \mathrm{dpa}$, worms were amputated a second time one segment anterior to the first amputation plane, and posterior parts were fixed for WMISH. Numbers of worms used for the different experiments are indicated in the corresponding figures and supplementary figures (and their legends).

\section{Scoring and statistical analysis}

The scoring system established in Planques et al. [37] was used to score worms during posterior regeneration and post-regenerative posterior growth. Graphic representation of transcriptomic, LUMA, and morphological experiments with corresponding statistical analyses were performed using Prism 7 software (GraphPad). Statistical tests that have been used are indicated in the legends of figures and supplementary figures. $\mathrm{R}$ was used for multiple correlation computation and representation. Holm correction was applied for significance calculation [101].

\section{Supplementary Information}

The online version contains supplementary material available at https://doi. org/10.1186/s12915-021-01074-5

Additional file 1: Figure S1. DNA methylation and NuRD toolkit genes in mammals. (A) Proteins involved in DNA methylation and demethylation include Dnmt3A/B responsible for de novo 5-methycytosine $(5 \mathrm{mC})$ formation, Dnmt1 required for $5 \mathrm{mC}$ maintenance during DNA replication, Uhrf1 which binds $5 \mathrm{mC}$ and recruits Dnmt1, and Tet and Tdg which are involved in active demethylation. Passive demethylation through cell divisions is also indicated. (B) The Nucleosome Remodeling and Deacetylase complex (NuRD complex) is recruited on methylated DNA and represses gene transcription. The NuRD complex is composed of two subcomplexes: one made of Mbd2/3 (which binds methylated cytosines), Gatad2a/b, and Chd3/4, and which acts on chromatin remodeling; and the other composed of Rbbp4/7, Mta1/2/3 and $\mathrm{Hdac1/2}$, which stimulates histone deacetylation. For the sake of simplicity, the NuRD complex is depicted in a schematic manner that does not reflect its real stoichiometry.

Additional file 2: Tables S1-S8. Supplementary Tables. Table S1: CpG o/e ratios obtained with Notos. Table S2: LUMA data. Table S3: Methylation levels of stretches of CpGs in Pdum-Histone H4 and Pdum-14-3-3-like genes defined by bisulfite pyrosequencing at different stages of the $P$. dumerilii life cycle. Table S4: Sequences used for phylogenetic analyses. Table S5: Lethality and autotomy induced by Decitabine treatment (short-term experiments). Table S6: Lethality and autotomy induced by Decitabine treatment (long-term experiments). Table S7: Primers used for $P$. dumerilii gene cloning and bisulfite pyrosequencing. Table S8: Databases used to retrieve sequences for phylogenetic analyses.

Additional file 3: Figure S2. Additional $\mathrm{CpG}$ o/e ratio calculations. Histograms of $\mathrm{CpG}$ o/e ratio for several species (whose name is indicated on top) for which this ratio has not been previously calculated. In each histogram, the red line indicates the estimated density, the vertical blue bar shows the estimated mean value, and the shaded blue bar represents bootstrap confidence intervals of $95 \%$. $\mathrm{PM}=$ probability mass. Clusters are those defined in Aliaga et al. [48]. The color code for metazoan groups is indicated and is as in Fig. 2.

Additional file 4: Figure S3. P. dumerilii $5 \mathrm{mC}$ and NuRD machinery genes and proteins. All identified $P$. dumerilii genes are listed with the identification of the corresponding gene model in the Pdumbase reference transcriptome [49], excepted for dnmt3, identified in our unpublished regeneration transcriptome. Schematic representations of $P$. dumerilii (Pdum) and corresponding Human (Hsap) proteins are also shown, highlighting conserved domains found in these proteins and the position of these domains. Sequences of the $P$. dumerilii and Human proteins can be found in Additional file 5 .

Additional file 5: Sequences used for phylogenetic analyses, multiple alignments, and phylogenetic trees. This file contains all protein sequences and multiple alignments used for phylogenetic analyses in fasta format, as well as the obtained phylogenetic trees in Newick format.

Additional file 6: Figure S4. Phylogenetic trees of $5 \mathrm{mC}$ and NuRD toolkit proteins. Maximum likelihood (ML) trees constructed with PhyML are shown. Statistical supports (aLRT values) for all nodes are indicated with a color code provided in the inset. Terminal branches are colored using the shown color code also used in Fig. 2. P. dumerilii sequences are in bold and indicated by arrows. (A) DNMT proteins. The three subfamilies DNMT1, 2 and 3 are indicated. In the DNMT3 subfamily, the vertebrate-specific groups DNMT3A, B and -like are also shown. We used a distantly related sequence (Dnmt5) from Acanthamoeba castellanii (Acas, an amoeba) as outgroup to root the phylogenetic tree. We also retrieved Dnmt sequences from two choanoflagellates species, Monosiga brevicollis (Mbre) and Salpingoeca rosetta (Sros), which all belong to the DNMT2 subfamily. (B) TET proteins. The three vertebrate-specific groups TET1, 2 and 3 are indicated. We used midpoint rooting for this tree as we were unable to find Tet genes in choanoflagellates or another suitable outgroup. (C) TDG. The phylogenetic tree is rooted using choanoflagellate sequences as outgroup. (D) UHRF. The two vertebrate-specific groups UHRF1 and 2 are indicated. We used midpoint rooting for this tree as we were unable to find Uhrf genes in choanoflagellates or another suitable outgroup. (E) MBD proteins. The two subfamilies MBD1/2/3 and MBD4 subfamilies are indicated. Vertebrate-specific groups are also shown. While not found in S. rosetta and M. brevicollis, a single Mbd gene was found in three other choanoflagellates (Helgoeca nana (Hnan), Salpingoeca urceolata (Surc), and Acanthoeca spectabilis (Aspe)) for which extensive transcriptomic data have been produced. Two of these 
choanoflagellate Mbd sequences (Hnan and Aspe) form a monophyletic group that was used as outgroup to root the tree, while the third one (Surc) clusters with MBD 4 proteins. (F) CHD proteins. The three subfamilies CHD1/2, CHD3/4/5 and CHD6/7/8/9 are indicated. Vertebrate-specific groups are also shown. We used the distantly related SNF2L1 sequence from Human as outgroup to root the phylogenetic tree. (G) Class I HDAC proteins. The three subfamilies HDAC1/2, HDAC3 and HDAC8 are indicated. Vertebrate-specific HDAC1 and 2 groups are also shown. Class II and IV HDACs from Human were used as outgroup to root the phylogenetic tree. We also retrieved HDACs from choanoflagellates, three of which clustering with the outgroup, two with HDAC3 proteins, and two with HDAC1/2 proteins. (H) RBBP4/7 proteins. Vertebrate-specific RBBP4 and 7 groups are shown. The phylogenetic tree is rooted using choanoflagellate sequences as outgroup. (I) MTA1/2/3 proteins. Vertebrate-specific MTA1, 2 and 3 groups are shown. (J) GATAD2 proteins. Vertebrate-specific GATA D2-alpha and GATAD2-beta groups are shown. For (I) and (J), midpoint rooting has been used in the absence of choanoflagellate members of these two gene families and the absence of other suitable outgroups.

Additional file 7: Figure S5. Expression level of $5 \mathrm{mC}$ and NuRD machinery genes during $P$. dumerilii development and along its life cycle. A histogram reporting FPKM values at 19 stages (developmental and adult stages) for all indicated genes is shown. The FPKM values from embryonic stages and those for the other stages cannot be compared, as having been calculated from two independent RNA-seq studies. These two datasets are therefore separated by a black vertical dashed line. Black horizontal dotted lines highlight a 5 FPKM threshold about which a gene can be considered as significantly expressed, as its expression can usually be detected by in situ hybridization [49]. Co-expression clusters are those defined by Chou et al. [49]. Hpf: hours post-fertilization; dpf: days postfertilization; mpf: months post-fertilization.

Additional file 8: Figure S6. A schematic representation of $P$. dumerilii posterior regeneration. On the top row is depicted a 3-4-month-old juvenile worm (with 30 to 40 segments). Its posterior part (5 segments, growth zone, and pygidum) is eliminated by amputation (the red dotted lines indicate the amputation plane). Regeneration occurs at the posterior extremity of the anterior body region. The region delineated by the dotted black lines corresponds to the part of the regenerating worms that is shown in WMISH pictures (Figs. 5 and S7). It comprises the posterior part of the posteriormost differentiated segment (S), in which parapodia (black arrows) associated with glands (asterisks) can be seen, plus the regenerated region (region indicated by the two-headed arrow; red dotted lines show the position of the amputation plane). Anterior is up and posterior down. The regenerated region increases in size as regeneration proceeds, from stage 1 to 5 of the process [37]. At stage 1 (reached 1 day postamputation, 1dpa), wound healing is achieved. A small blastema is formed at stage 2 (2dpa) and molecular analyses indicate that the growth zone is already regenerated at this stage. A regenerated anus can be observed at this stage. At stage 3 (3dpa), the regenerated region has increased in size and small anal cirri are present. The use of molecular markers showed that the growth zone has already produced at least one segment and tissue differentiation has started in the pygidium. The large blastema found at stage 4 ( $4 \mathrm{dpa}$ ) contains a differentiated pygidium with long anal cirri. Tissue differentiation also starts in the two or more segments that have been produced by the growth zone. Segments are however still not morphologically visible. Stage 5 ( $5 \mathrm{dpa}$ ) corresponds to the end of regeneration. At this stage, a fully differentiated pygidium is found, and segmentation of the regenerated region becomes visible at the morphological level (presence of visible parapodial primordia for example). From this stage onwards, post-regenerative posterior growth starts and a growing number of morphologically well visible segments with parapodia and segmental grooves between adjacent segments is observed.

Additional file 9: Figure S7. Additional expression data of $5 \mathrm{mC}$ and NuRD genes during regeneration. Whole-mount in situ hybridizations (WMISH) for the genes whose name is indicated are shown. In all panels except $\mathrm{E}$, anterior is up and the regeneration stage for each picture is indicated. In all panels except $E$, red dotted lines indicate the amputation plane. Dorsal (D) and posterior (P) views are shown. Light blue arrowheads = ectodermal growth zone, light blue arrows = ectoderm of developing segment, red arrows = groups of internal cells in the segment adjacent to the amputation plane.

Additional file 10: Figure S8. Schematic representation of expression patterns of $5 \mathrm{mC}$ and NuRD genes during regeneration. In all panels, anterior is up and the regeneration stage for each drawing is indicated. Ventral schematic representations are shown for all stages and a dorsal schematic representation is also provided for stage 5. The color code for the different tissues is provided in the inset.

Additional file 11: Figure S9. Expression of $5 \mathrm{mC}$ and NuRD genes in worms at 15 days post-amputation. Whole-mount in situ hybridizations (WMISH) for the genes whose name is indicated are shown at 15 days post-amputation (15dpa). These worms are used as a proxy for nonamputated worms [36]. In all panels, anterior is up. All images are ventral views. Dark blue arrows point to an ectodermal expression including an expression in the ventral nerve cord, red arrows point to mesodermal cells of the developing segments, and red arrowheads to the mesodermal part of the growth zone. We failed to detect significant expression for Pdum-chd1/2.

Additional file 12: Figure S10. Expression of $5 \mathrm{mC}$ and NuRD genes in worms immediately after amputation. Whole-mount in situ hybridizations (WMISH) for the genes whose name is indicated are shown. In all panels, anterior is up. Only weak and diffuse expression was found for the genes that are shown and we failed to detect significant expression for the three other genes (Pdum-mbd1/2/3, Pdum-hdac8 and Pdum-chd1/2). Pdum-dnmt1 and $P$ duchd $3 / 4 / 5 B$ are expressed in a few ectodermal cells (dark blue arrows); Pdum-dnmt3, Pdum-tet and Pdum-hdac3 are expressed in mesodermal cells (red arrows); and Pdum-tdg and Pdum-chd6/7/8/9 are largely expressed in the ectoderm including the ventral nerve cord (light blue arrows).

Additional file 13: Figure S11. Rate of segment addition and individual scoring of Decitabine-treated worms. (A) Graphic representation of the rate of segment addition in controls (DMSO 0.01\% and sea water) and Decitabine-treated worms (worms that showed autotomy were excluded). (B-F) Graphic representation of scoring of individual control (B and C) and Decitabine-treated (D-F) worms until 25dpa. Two experiments, mean $\pm \mathrm{SD}$. For the analysis of the rate of segment addition, 1-way ANOVA was performed with Dunnett post hoc test (**: $p<0.01$; ***: $\mathrm{p}<0.001 ; * * *: \mathrm{p}<0.0001)$. For conditions comparison, 2-way ANOVA was performed (Source of variation: Time $p<0.0001$, Treatment $p<$ 0.0001 , Interaction $p=0.0875$ ) with Dunnett post hoc test $\left(^{*}: p<0.05\right.$; ** $p<0.01$; ${ }^{* * *}: p<0.001$ ). The number of worms used for these experiments is indicated in the figure.

Additional file 14: Figure S12. Classification of Decitabine-treated worms based on morphological defects. Three classes of worms can be defined based on the reported morphological defects. For each class, representative worms at five different time points after amputation are shown. Green arrowheads = characteristic constriction between the nonregenerated and regenerated regions, pink arrows $=$ very reduced or absent anal cirri, blue arrows = reduced/abnormal anal cirri, green arrows = narrowed regenerated region, black arrowheads $=$ abnormal parapodia.

Additional file 15: Figure S13. Multiple correlation analysis between regeneration and segment addition. (A-B) Statistical analysis of the regeneration score correlation in (A) control and (B) Decitabine-treated worms. Blue dots show positive correlations and red dots negative correlations. The dot size is proportional to the correlation score and significant correlations are highlighted with asterisks. Spearman correlation with Holm post hoc test ( ${ }^{*}$ for $p<0.05$ ).

Additional file 16: Figure S14. Analysis of long-term Decitabine effects on regenerating and growing worms after a second amputation. (A) Schematic representation of the experimental design. Worms were treated with Decitabine $(10 \mu \mathrm{M}, 50 \mu \mathrm{M}$, or $100 \mu \mathrm{M})$, or DMSO $(0,01 \%$; control) or kept in normal sea water (control) for five days following amputation ( 5 days post-amputation, dpa). Decitabine was washed out and worms were kept in normal sea water until $25 \mathrm{dpa}$ (see Fig. 8). A second amputation was performed (which removed the regenerated region) and worms were kept in normal sea water until 18 days post-second amputation (18dpSa). Observations were done at indicated time points (pink bars). (B) Graphic representation of the stages reached by control worms 
(normal sea water and DMSO 0,01\%) and Decitabine-treated worms after the second amputation. A significant delay was observed for worms treated with $10 \mu \mathrm{M}$ as compared to controls at 18dpSa. Worms treated with the other concentrations of Decitabine regenerated and added segments similarly to controls. Two experiments, mean $\pm S D, 2$-way. ANOVA ( $p$ value: Time $p<0.0001$, Treatment $p=0.0283$, Interaction $p=0.0663$ ) with Tukey post hoc test $(*: p<0.05)$. Only $p$ values corresponding to the comparison to normal sea water are shown (similar values were obtained for the comparison to DMSO controls). The number of worms used for these experiments is indicated in the figure. (C) Most Decitabine worms that were class 1 or class 2 at $25 \mathrm{dpa}$ (after first amputation) regenerated after a second amputation without any morphological abnormalities $(84,2 \%$ and $88,1 \%$, respectively), but some of them show minor morphological defects in parapodia and chaetae formation $15,8 \%$ and $11,9 \%$, respectively). ( $\mathrm{D}$ and $\mathrm{E}$ ) Multiple correlation analysis between regeneration/segment addition after first and second amputation. Only positive correlations were observed for both control and Decitabinetreated worms after a second amputation. Blue dots indicate positive correlations and red dots negative correlations. The dot size is proportional to the correlation score and significant correlations are highlighted with stars. Spearman correlation with Holm post hoc test (* for $p<0.05)$.

\section{Acknowledgements}

We thank all Vervoort lab members for helpful discussions and feedback on the manuscript. We are grateful to Maxim Greenberg and Pierre-Antoine Defossez for helpful discussions and comments on the manuscript. We thank Haley Flom for her diligent proofreading of the manuscript. We would like to thank the anonymous reviewers and BMC Biology's editorial team for their careful reading of our manuscript and their many insightful comments and suggestions. We thank the direction of the Institut Jacques Monod for its support. We are grateful to the teams of Eric Rottinger, Sandra Duharcourt, and Hector Escriva for providing us with genomic DNA from N. vectensis, $D$. melanogaster, and B. lanceolatum, respectively. Animal facility members are thanked for their help with the worm culture. Tom Anerot-Rigo, Thibault Bidolet, Camille Kergavat, Maude Marchais, Erwan Martin, Edouard Riey, and Anne Sauterau are thanked for their help with experiment setup. We acknowledge the Functional Epigenomics facility of the Epigenetics and Cell Fate unit (UMR7216) for its contribution to this work.

\section{Authors' contributions}

A.P., E.G., and M.V. designed the study, performed data analysis, and wrote the manuscript. A.P performed most experiments and phylogenetic analyses. L.F. performed LUMA and bisulfite pyrosequencing experiments. C.G. performed $\mathrm{CpG}$ o/e ratio calculations. P.K. contributed to phylogenetic analyses. E.G. contributed to in situ hybridizations and DNA extractions. All authors read and approved the final manuscript.

\section{Funding}

This work was supported by funding from Labex Who Am I? laboratory of excellence (No. ANR-11-LABX-0071) funded by the French Government through its Investments for the Future program operated by the Agence Nationale de la Recherche under grant No. ANR-11-IDEX-0005-01, Centre National de la Recherche Scientifique, Université de Paris, Agence Nationale de la Recherche (grant TELOBLAST no. ANR-16-CE91-0007), the Association pour la Recherche sur le Cancer (grant PJA 20191209482), and the Ligue Nationale Contre le Cancer (grant RS20/75-20). This work also benefits from the support of LabEx CeMEB, an ANR « Investissements d'avenir » program (ANR-10LABX-04-01) and the Environmental Epigenomics Core Service at IHPE. This study is set within the framework of the "Laboratoire d'Excellence (LabEx) » TULIP (ANR-10-LABX-41). The funding agencies had no roles in the design of the study or collection, analysis, and interpretation of data, or in writing the manuscript.

\section{Availability of data and materials}

All data generated or analyzed during this study are included in this published article, its supplementary information files and publicly available repositories. Accession numbers for $P$. dumerilii DNA methylation and NuRD tookit genes are GenBank MW250929 to MW250948. Expression values from RNA-seq data were retrieved from PdumBase $[59,102]$. Supporting data values can be found in Additional file 2: Table S1-S6. Protein sequences, multiple alignments, and phylogenetic trees can be found in Additional file 5 .

\section{Declarations}

Ethics approval and consent to participate

Not applicable.

\section{Consent for publication}

Not applicable.

\section{Competing interests}

The authors declare that they have no competing interests.

\section{Author details}

'Université de Paris, CNRS, Institut Jacques Monod, F-75006 Paris, France.

${ }^{2} U$ niversité de Paris, CNRS, Epigenetics and Cell Fate, F-75006 Paris, France. ${ }^{3} \mathrm{H}$ HPE, Univ Montpellier, CNRS, IFREMER, Univ Perpignan Via Domitia, F-66860 Perpignan, France.

Received: 13 November 2020 Accepted: 16 June 2021

Published online: 03 August 2021

\section{References}

1. Greally JM. A user's guide to the ambiguous word "epigenetics". Nat Rev Mol Cell Biol. 2018;19(4):207-8. https://doi.org/10.1038/nrm.2017.135.

2. Skvortsova K, lovino N, Bogdanović O. Functions and mechanisms of epigenetic inheritance in animals. Nat Rev Mol Cell Biol. 2018;19(12):774-90. https://doi.org/10.1038/s41580-018-0074-2.

3. Barrero MJ, Belmonte JCl. Regenerating the epigenome. EMBO Rep. 2011; 12(3):208-15. https://doi.org/10.1038/embor.2011.10.

4. Atlasi $Y$, Stunnenberg HG. The interplay of epigenetic marks during stem cell differentiation and development. Nat Rev Genet. 2017;18(11):643-58. https://doi.org/10.1038/nrg.2017.57.

5. Law JA, Jacobsen SE. Establishing, maintaining and modifying DNA methylation patterns in plants and animals. Nat Rev Genet. 2010;11(3):20420. https://doi.org/10.1038/nrg2719.

6. Jones PA. Functions of DNA methylation: islands, start sites, gene bodies and beyond. Nat Rev Genet. 2012;13(7):484-92. https://doi.org/10.1038/ nrg3230.

7. Greenberg MVC, Bourc'his D. The diverse roles of DNA methylation in mammalian development and disease. Nat Rev Mol Cell Biol. 2019;20(10): 590-607. https://doi.org/10.1038/s41580-019-0159-6.

8. Schmitz RJ, Lewis ZA, Goll MG. DNA methylation: shared and divergent features across eukaryotes. Trends Genet. 2019;35(11):818-27. https://doi. org/10.1016/j.tig.2019.07.007.

9. de Mendoza A, Lister R, Bogdanović O. Evolution of DNA methylome diversity in eukaryotes. J Mol Biol. 2019;432:1687-705.

10. Zemach A, McDaniel IE, Silva P, Zilberman D. Genome-wide evolutionary analysis of eukaryotic DNA methylation. Science. 2010;328:916-9.

11. Suzuki MM, Bird A. DNA methylation landscapes: provocative insights from epigenomics. Nat Rev Genet. 2008;9(6):465-76. https://doi.org/10.1038/ nrg2341.

12. Zemach A, Zilberman D. Evolution of eukaryotic DNA methylation and the pursuit of safer sex. Curr Biol. 2010;20(17):R780-5. https://doi.org/10.1016/j. cub.2010.07.007.

13. Zilberman D. An evolutionary case for functional gene body methylation in plants and animals. Genome Biol. 2017;18(1):87. https://doi.org/10.1186/s13 059-017-1230-2

14. Boland MJ, Nazor KL, Loring JF. Epigenetic regulation of pluripotency and differentiation. Circ Res. 2014;115(2):311-24. https://doi.org/10.1161/ CIRCRESAHA.115.301517.

15. Ponger L, Li W-H. Evolutionary diversification of DNA methyltransferases in eukaryotic genomes. Mol Biol Evol. 2005;22:1119-28.

16. Bronner C, Alhosin M, Hamiche A, Mousli M. Coordinated dialogue between UHRF1 and DNMT1 to ensure faithful inheritance of methylated DNA patterns. Genes. 2019;10(1). https://doi.org/10.3390/genes10010065.

17. Goll MG, Kirpekar F, Maggert KA, Yoder JA, Hsieh C-L, Zhang X, et al. Methylation of tRNAAsp by the DNA methyltransferase homolog Dnmt2. Science. 2006;311:395-8. 
18. Bhutani N, Burns DM, Blau HM. DNA demethylation dynamics. CELL. 2011; 146(6):866-72. https://doi.org/10.1016/j.cell.2011.08.042.

19. Wu X, Zhang Y. TET-mediated active DNA demethylation: mechanism, function and beyond. Nat Rev Genet. 2017;18(9):517-34. https://doi.org/10.1 038/nrg.2017.33.

20. Buck-Koehntop BA, Defossez P-A. On how mammalian transcription factors recognize methylated DNA. Epigenetics. 2013;8(2):131-7. https://doi.org/1 0.4161/epi.23632.

21. Du Q, Luu P-L, Stirzaker C, Clark SJ. Methyl-CpG-binding domain proteins: readers of the epigenome. Epigenomics. 2015;7(6):1051-73. https://doi.org/1 0.2217/epi.15.39

22. Albalat R, Marti-Solans J, Cañestro C. DNA methylation in amphioxus: from ancestral functions to new roles in vertebrates. Brief Funct Genomics. 2012; 11(2):142-55. https://doi.org/10.1093/bfgp/els009.

23. Allen HF, Wade PA, Kutateladze TG. The NuRD architecture. Cell Mol Life Sci. 2013;70(19):3513-24. https://doi.org/10.1007/s00018-012-1256-2.

24. Torchy MP, Hamiche A, Klaholz BP. Structure and function insights into the NuRD chromatin remodeling complex. Cell Mol Life Sci. 2015;72(13):2491507. https://doi.org/10.1007/s00018-015-1880-8.

25. Low JKK, Silva APG, Tabar MS, Torrado M, Webb SR, Parker BL, et al. The nucleosome remodeling and deacetylase complex has an asymmetric dynamic, and modular architecture. Cell Rep. 2020;33(9):108450. https://doi. org/10.1016/j.celrep.2020.108450.

26. del Gaudio R, Giaimo RD, Geraci G. Genome methylation of the marine annelid worm Chaetopterus variopedatus: methylation of a $\mathrm{CpG}$ in an expressed H1 histone gene. FEBS Lett. 1997;417(1):48-52. https://doi.org/1 $0.1016 / 50014-5793(97) 01262-3$.

27. Dabe EC, Sanford RS, Kohn AB, Bobkova Y, Moroz LL. DNA methylation in basal metazoans: insights from ctenophores. Integr Comp Biol. 2015;55(6): 1096-110. https://doi.org/10.1093/icb/icv086.

28. Kesäniemi JE, Heikkinen L, Knott KE. DNA methylation and potential for epigenetic regulation in Pygospio elegans. PLoS ONE. 2016;11:e0151863.

29. Cramer JM, Pohlmann D, Gomez F, Mark L, Kornegay B, Hall C, et al. Methylation specific targeting of a chromatin remodeling complex from sponges to humans. Sci Rep. 2017;7(1):40674. https://doi.org/10.1038/srep4 0674 .

30. Geyer KK, Niazi UH, Duval D, Cosseau C, Tomlinson C, Chalmers IW, et al. The Biomphalaria glabrata DNA methylation machinery displays spatial tissue expression, is differentially active in distinct snail populations and is modulated by interactions with Schistosoma mansoni. PLoS Negl Trop Dis. 2017;11(5):e0005246. https://doi.org/10.1371/journal.pntd.0005246.

31. Riviere G, He Y, Tecchio S, Crowell E, Gras M, Sourdaine P, et al. Dynamics of DNA methylomes underlie oyster development. PLoS Genet. 2017;13(6): e1006807. https://doi.org/10.1371/journal.pgen.1006807.

32. Kao D, Lai AG, Stamataki E, Rosic S, Konstantinides N, Jarvis E, et al. The genome of the crustacean Parhyale hawaiensis, a model for animal development, regeneration, immunity and lignocellulose digestion. eLife. 2016:5:e20062. https://doi.org/10.7554/eLife.20062.

33. de Mendoza A, Hatleberg WL, Pang K, Leininger S, Bogdanović O, Pflueger $\mathrm{J}$, et al. Convergent evolution of a vertebrate-like methylome in a marine sponge. Nat Ecol Evol. 2019;3:1464-73.

34. Telford MJ, Budd GE, Philippe H. Phylogenomic insights into animal evolution. Curr Biol. 2015;25:R876-87.

35. Fischer AH, Henrich T, Arendt D. The normal development of Platynereis dumerilii (Nereididae, Annelida). Front Zool. 2010;7(1):31. https://doi.org/1 0.1186/1742-9994-7-31.

36. Gazave E, Béhague J, Laplane L, Guillou A, Préau L, Demilly A, et al. Posterior elongation in the annelid Platynereis dumerilii involves stem cells molecularly related to primordial germ cells. Dev Biol. 2013;382(1):246-67. https://doi.org/10.1016/j.ydbio.2013.07.013

37. Planques A, Malem J, Parapar J, Vervoort M, Gazave E. Morphological, cellular and molecular characterization of posterior regeneration in the marine annelid Platynereis dumerilii. Dev Biol. 2019;445(2):189-210. https:/ doi.org/10.1016/j.ydbio.2018.11.004.

38. Katsuyama T, Paro R. Epigenetic reprogramming during tissue regeneration. FEBS Lett. 2011;585(11):1617-24. https://doi.org/10.1016/j.febslet.2011.05.010.

39. Hirose K, Shimoda N, Kikuchi Y. Transient reduction of 5-methylcytosine and 5-hydroxymethylcytosine is associated with active DNA demethylation during regeneration of zebrafish fin. Epigenetics. 2013;8(9):899-906. https:// doi.org/10.4161/epi.25653.
40. Aguilar C, Gardiner DM. DNA methylation dynamics regulate the formation of a regenerative wound epithelium during axolotl limb regeneration. PLoS ONE. 2015;10:e0134791.

41. Elango N, Hunt BG, Goodisman MAD, Yi SV. DNA methylation is widespread and associated with differential gene expression in castes of the honeybee, Apis mellifera. Proc Natl Acad Sci U S A. 2009;106:11206-11.

42. Yi SV, Goodisman MAD. Computational approaches for understanding the evolution of DNA methylation in animals. Epigenetics. 2009;4(8):551-6. https://doi.org/10.4161/epi.4.8.10345.

43. Bulla I, Aliaga B, Lacal V, Bulla J, Grunau C, Chaparro C. Notos - a galaxy tool to analyze CpN observed expected ratios for inferring DNA methylation types. BMC Bioinform. 2018;19:105.

44. Bird AP. DNA methylation and the frequency of $\mathrm{CpG}$ in animal DNA. Nucleic Acids Res. 1980;8(7):1499-504. https://doi.org/10.1093/nar/8.7.1499.

45. Sved J, Bird $\mathrm{A}$. The expected equilibrium of the $\mathrm{CpG}$ dinucleotide in vertebrate genomes under a mutation model. Proc Natl Acad Sci U S A. 1990;87(12):4692-6. https://doi.org/10.1073/pnas.87.12.4692.

46. Fryxell KJ, Moon W-J. CpG mutation rates in the human genome are highly dependent on local GC content. Mol Biol Evol. 2005;22(3):650-8. https://doi. org/10.1093/molbev/msi043.

47. Flores KB, Amdam GV. Deciphering a methylome: what can we read into patterns of DNA methylation? J Exp Biol. 2011;214(Pt 19):3155-63.

48. Aliaga B, Bulla I, Mouahid G, Duval D, Grunau C. Universality of the DNA methylation codes in Eucaryotes. Sci Rep. 2019;9(1):173. https://doi.org/10.1 038/s41598-018-37407-8.

49. Chou H-C, Pruitt MM, Bastin BR, Schneider SQ. A transcriptional blueprint for a spiral-cleaving embryo. BMC Genomics. 2016;17(1):552. https://doi.org/1 0.1186/s12864-016-2860-6.

50. Tweedie S, Charlton J, Clark V, Bird A. Methylation of genomes and genes at the invertebrate-vertebrate boundary. Mol Cell Biol. 1997;17(3):1469-75. https://doi.org/10.1128/MCB.17.3.1469.

51. Garcia RN, D'Ávila MF, Robe L, da Silva Loreto EL, Panzera Y, de Heredia FO, et al. First evidence of methylation in the genome of Drosophila willistoni. Genetica. 2007:131(1):91-105. https://doi.org/10.1007/s10709-006-9116-3.

52. Habibi E, Brinkman AB, Arand J, Kroeze LI, Kerstens HHD, Matarese F, et al. Whole-genome bisulfite sequencing of two distinct interconvertible DNA methylomes of mouse embryonic stem cells. Cell Stem Cell. 2013;13:360-9.

53. Karimi $M$, Johansson $S$, Stach $D$, Corcoran $M$, Grandér $D$, Schalling $M$, et al. LUMA (LUminometric Methylation Assay)--a high throughput method to the analysis of genomic DNA methylation. Exp Cell Res. 2006;312(11):198995. https://doi.org/10.1016/j.yexcr.2006.03.006.

54. Karimi M, Johansson S, Ekström TJ. Using LUMA: a Luminometric-based assay for global DNA-methylation. Epigenetics. 2006;1:45-8.

55. Šestáková Š, Šálek C, Remešová H. DNA methylation validation methods: a coherent review with practical comparison. Biol Proced Online. 2019;21(1): 19. https://doi.org/10.1186/s12575-019-0107-z.

56. Liu J, Hu H, Panserat S, Marandel L. Evolutionary history of DNA methylation related genes in chordates: new insights from multiple whole genome duplications. Sci Rep. 2020;10(1):970. https://doi.org/10.1038/s41598-02057753-w.

57. Gregoretti I. Molecular evolution of the histone deacetylase family: functional implications of phylogenetic analysis. J Mol Biol. 2004;338:17-31.

58. Ledent V, Vervoort M. Comparative genomics of the class 4 histone deacetylase family indicates a complex evolutionary history. BMC Biol. 2006; 4(1):24. https://doi.org/10.1186/1741-7007-4-24.

59. Chou H-C, Acevedo-Luna N, Kuhlman JA, Schneider SQ. PdumBase: a transcriptome database and research tool for Platynereis dumerilii and early development of other metazoans. BMC Genomics. 2018;19:618.

60. Conzelmann M, Williams EA, Krug K, Franz-Wachtel M, Macek B, Jékely G. The neuropeptide complement of the marine annelid Platynereis dumerilii. BMC Genomics. 2013;14(1):906. https://doi.org/10.1186/1471-2164-14-906.

61. Christman JK. 5-Azacytidine and 5-aza-2'-deoxycytidine as inhibitors of DNA methylation: mechanistic studies and their implications for cancer therapy. Oncogene. 2002;21(35):5483-95. https://doi.org/10.1038/sj.onc.1205699.

62. Brueckner B, Boy RG, Siedlecki P, Musch T, Kliem HC, Zielenkiewicz P, et al. Epigenetic reactivation of tumor suppressor genes by a novel small-molecule inhibitor of human DNA methyltransferases. Cancer Res. 2005;65:6305-11.

63. Stresemann C, Lyko F. Modes of action of the DNA methyltransferase inhibitors azacytidine and decitabine. Int J Cancer. 2008;123(1):8-13. https:// doi.org/10.1002/ijc.23607. 
64. Ramos M-P, Wijetunga NA, McLellan AS, Suzuki M, Greally JM. DNA demethylation by 5-aza-2'-deoxycytidine is imprinted, targeted to euchromatin, and has limited transcriptional consequences. Epigenetics Chromatin. 2015;8(1):11. https://doi.org/10.1186/s13072-015-0004-x.

65. Dattani A, Sridhar D, Aboobaker AA. Planarian flatworms as a new model system for understanding the epigenetic regulation of stem cell pluripotency and differentiation. Semin Cell Dev Biol. 2018;87:79-94.

66. Jaber-Hijazi F, Lo PJKP, Mihaylova Y, Foster JM, Benner JS, Romero BT, et al. Planarian MBD2/3 is required for adult stem cell pluripotency independently of DNA methylation. Dev Biol. 2013;384:141-53.

67. Li E, Zhang Y. DNA methylation in mammals. Cold Spring Harb Perspect Biol. 2014;6(5):a019133. https://doi.org/10.1101/cshperspect.a019133.

68. Kyono Y, Raj S, Sifuentes CJ, Buisine N, Sachs L, Denver RJ. DNA methylation dynamics underlie metamorphic gene regulation programs in Xenopus tadpole brain. Dev Biol. 2020;462(2):180-96. https://doi.org/10.1016/j.ydbio.2 020.03.013.

69. Lyko F, Foret S, Kucharski R, Wolf S, Falckenhayn C, Maleszka R. The honey bee epigenomes: differential methylation of brain DNA in queens and workers. PLoS Biol. 2010;8(11):e1000506. https://doi.org/10.1371/journal.pbio.1000506.

70. Bewick AJ, Vogel KJ, Moore AJ, Schmitz RJ. Evolution of DNA methylation across insects. Mol Biol Evol. 2017;34(3):654-65. https://doi.org/10.1093/ molbev/msw264.

71. Raible F, Tessmar-Raible K, Osoegawa K, Wincker P, Jubin C, Balavoine G, et al. Vertebrate-type intron-rich genes in the marine annelid Platynereis dumerilii. Science. 2005;310:1325-6.

72. Williams EA, Jékely $\mathrm{G}$. Towards a systems-level understanding of development in the marine annelid Platynereis dumerilii. Curr Opin Genet Dev. 2016;39:175-81. https://doi.org/10.1016/j.gde.2016.07.005.

73. Riviere G, Wu G-C, Fellous A, Goux D, Sourdaine P, Favrel P. DNA methylation is crucial for the early development in the Oyster C. gigas. Mar Biotechnol. 2013;15:739-53

74. Kumar S, Kim Y. An endoparasitoid wasp influences host DNA methylation Sci Rep. 2017;7(1):43287. https://doi.org/10.1038/srep43287.

75. Xu G, Zhang J, Lyu H, Song Q, Feng Q, Xiang $H$, et al. DNA methylation mediates BmDeaf1-regulated tissue- and stage-specific expression of BmCHSA2b in the silkworm, Bombyx mori. Epigenetics Chromatin. 2018;11:32.

76. Prud'homme B, de Rosa R, Arendt D, Julien J-F, Pajaziti R, Dorresteijn AWC, et al. Arthropod-like expression patterns of engrailed and wingless in the annelid Platynereis dumerilii suggest a role in segment formation. Curr Biol. 2003:13(21):1876-81. https://doi.org/10.1016/j.cub.2003.10.006.

77. Starunov W, Dray N, Belikova EV, Kerner P, Vervoort M, Balavoine G. A metameric origin for the annelid pygidium? BMC Evol Biol. 2015;15(1):25. https://doi.org/10.1186/s12862-015-0299-z.

78. Rebscher N, Zelada-González F, Banisch TU, Raible F, Arendt D. Vasa unveils a common origin of germ cells and of somatic stem cells from the posterior growth zone in the polychaete Platynereis dumerilii. Dev Biol. 2007;306(2):599-611. https://doi.org/10.1016/j.ydbio.2007.03.521.

79. Issa J-PJ, Kantarjian HM. Targeting DNA methylation. Clin Cancer Res. 2009; 15(12):3938-46. https://doi.org/10.1158/1078-0432.CCR-08-2783.

80. Sato T, Issa J-PJ, Kropf P. DNA hypomethylating drugs in cancer therapy. Cold Spring Harb Perspect Med. 2017;7:a026948.

81. Demilly A, Steinmetz P, Gazave E, Marchand L, Vervoort M. Involvement of the $\mathrm{Wnt} / \beta$-catenin pathway in neurectoderm architecture in Platynereis dumerilii. Nat Commun. 2013;4(1):1915. https://doi.org/10.1038/ncomms2915.

82. Luz-Madrigal A, Grajales-Esquivel E, Tangeman J, Kosse S, Liu L, Wang K, et al. DNA demethylation is a driver for chick retina regeneration. Epigenetics. 2020;5:1-22.

83. Juliano CE, Swartz SZ, Wessel GM. A conserved germline multipotency program. Development. 2010;137:4113-26.

84. Chen T, Ueda Y, Dodge JE, Wang Z, Li E. Establishment and maintenance of genomic methylation patterns in mouse embryonic stem cells by Dnmt3a and Dnmt3b. Mol Cell Biol. 2003;23:5594-605.

85. Sheaffer KL, Kim R, Aoki R, Elliott EN, Schug J, Burger L, et al. DNA methylation is required for the control of stem cell differentiation in the small intestine. Genes Dev. 2014;28(6):652-64. https://doi.org/10.1101/gad.230318.113.

86. Trowbridge JJ, Orkin SH. DNA methylation in adult stem cells: New insights into self-renewal. Epigenetics. 2014;5:189-93.

87. Laker RC, Ryall JG. DNA methylation in skeletal muscle stem cell specification, proliferation, and differentiation. Stem Cells Int. 2016;2016:5725927.
88. Altschul SF, Madden TL, Schäffer AA, Zhang J, Zhang Z, Miller W, et al. Gapped BLAST and PSI-BLAST: a new generation of protein database search programs. Nucleic Acids Res. 1997;25(17):3389-402. https://doi.org/10.1093/nar/25.17.3389.

89. Mitchell AL, Attwood TK, Babbitt PC, Blum M, Bork P, Bridge A, et al. InterPro in 2019: improving coverage, classification and access to protein sequence annotations. Nucleic Acids Res. 2019;47(D1):D351-60. https://doi.org/10.1 093/nar/gky1100.

90. Marchler-Bauer A, Derbyshire MK, Gonzales NR, Lu S, Chitsaz F, Geer LY, et al. CDD: NCBl's conserved domain database. Nucleic Acids Res. 2015; 43(D1):D222-6. https://doi.org/10.1093/nar/gku1221.

91. Edgar RC. MUSCLE: multiple sequence alignment with high accuracy and high throughput. Nucleic Acids Res. 2004;32(5):1792-7. https://doi.org/10.1 093/nar/gkh340.

92. Zimmermann L, Stephens A, Nam S-Z, Rau D, Kübler J, Lozajic M, et al. A completely reimplemented MPI bioinformatics toolkit with a new HHpred server at its core. J Mol Biol. 2018;430(15):2237-43. https://doi.org/10.1016/j. jmb.2017.12.007.

93. Criscuolo A, Gribaldo S. BMGE (Block Mapping and Gathering with Entropy): a new software for selection of phylogenetic informative regions from multiple sequence alignments. BMC Evol Biol. 2010;10(1):210. https://doi. org/10.1186/1471-2148-10-210.

94. Gouy M, Guindon S, Gascuel O. SeaView version 4: a multiplatform graphical user interface for sequence alignment and phylogenetic tree building. Mol Biol Evol. 2010;27(2):221-4. https://doi.org/10.1093/molbev/msp259.

95. Guindon S, Gascuel O. A simple, fast, and accurate algorithm to estimate large phylogenies by maximum likelihood. Syst Biol. 2003;52(5):696-704. https://doi.org/10.1080/10635150390235520.

96. Guindon S, Lethiec F, Duroux P, Gascuel O. PHYML Online--a web server for fast maximum likelihood-based phylogenetic inference. Nucleic Acids Res. 2005;33(Web Server):W557-9. https://doi.org/10.1093/nar/gki352.

97. Lefort V, Longueville J-E, Gascuel O. SMS: smart model selection in PhyML. Mol Biol Evol. 2017;34(9):2422-4. https://doi.org/10.1093/molbev/msx149.

98. Anisimova M, Gascuel O. Approximate likelihood-ratio test for branches: a fast, accurate, and powerful alternative. Syst Biol. 2006;55:539-52.

99. Anisimova M, Gil M, Dufayard J-F, Dessimoz C, Gascuel O. Survey of branch support methods demonstrates accuracy, power, and robustness of fast likelihood-based approximation schemes. Syst Biol. 2011;60:685-99.

100. Tessmar-Raible K, Steinmetz PRH, Snyman H, Hassel M, Arendt D. Fluorescent two-color whole mount in situ hybridization in Platynereis dumerilii (Polychaeta, Annelida), an emerging marine molecular model for evolution and development. BioTechniques. 2005;39(4):460-4. https://doi. org/10.2144/000112023.

101. Gaetano J. Holm-Bonferroni Sequential Correction: an EXCEL calculator - Ver. 1.2. 2013. https://doi.org/10.13140/RG.2.1.3920.0481.

102. PdumBase the Platynereis dumerilii database. Dr. Schneider's lab. lowa State University. 2018. http://140.109.48.81/platynereis/controller.php?action= home. Accessed 30 May 2021.

\section{Publisher's Note}

Springer Nature remains neutral with regard to jurisdictional claims in published maps and institutional affiliations.

Ready to submit your research? Choose BMC and benefit from:

- fast, convenient online submission

- thorough peer review by experienced researchers in your field

- rapid publication on acceptance

- support for research data, including large and complex data types

- gold Open Access which fosters wider collaboration and increased citations

- maximum visibility for your research: over $100 \mathrm{M}$ website views per year

At BMC, research is always in progress.

Learn more biomedcentral.com/submissions 